\title{
EL TJUE COMO ACTOR DE LA CONSTITUCIONALIDAD EN EL ESPACIO JURÍDICO EUROPEO: LA IMPORTANCIA DEL DIÁLOGO JUDICIAL LEAL CON LOS TRIBUNALES CONSTITUCIONALES Y CON EL TEDH
}

\author{
JOSÉ MARTÍN Y PÉREZ DE NANCLARES \\ Catedrático de Derecho Internacional Público \\ Universidad de Salamanca
}

\section{SUMARIO}

I. Aspectos generales: la existencia de tres 'titanes judiciales' en el triángulo constitucional europeo de los derechos humanos. II. La importancia del diálogo judicial en el espacio jurídico europeo multinivel: los derechos humanos como banco de pruebas para el triángulo judicial constitucional europeo. III. La relación entre el TJUE y los tribunales constitucionales nacionales: una historia de ambiciones comunes razonablemente bien encauzada. IV. La relación entre el TJUE y el TEDH: el nuevo reto constitucional (pendiente) del Tribunal de Justicia. V. Consideraciones finales: una de cal y otra de arena.

\section{ASPECTOS GENERALES: LA EXISTENCIA DE TRES 'TITANES JUDICIALES' EN EL TRIÁNGULO CONSTITUCIONAL EUROPEO DE LOS DERECHOS HUMANOS}

En cualquier contribución a un número monográfico sobre el Tribunal de Justicia de la Unión Europea (TJUE) existen dos cuestiones previas que difícilmente pueden pasarse por alto en el presente momento. La primera es de carácter extrajurídico y está conectada con el actual contexto de la Unión Europea (UE), mientras que la segunda se refiere a la inconfesada — pero comprensible - voluntad jurisdiccional de tres tribunales diferentes por intentar mantener el 'derecho a la última palabra' sobre un mismo espacio físico.

En efecto, en primer lugar, nada que afecte a la UE y a sus instituciones, incluido por supuesto su Alto Tribunal, puede abstraerse en la actualidad del 
delicado momento por el que atraviesa el proceso de integración europea. Así, de entrada, el reto indudable que plantea el Brexit contamina cualquier acercamiento jurídico a la Unión ${ }^{1}$. Pero este reto se inserta, a su vez, en un frágil escenario más amplio en el que, retomando las significativas palabras pronunciadas por el presidente de la Comisión ante el Parlamento Europeo en el último debate sobre el Estado de la Unión, bien puede hablarse de una verdadera 'crisis existencial' de la Unión ${ }^{2}$. Ciertamente, nunca antes la Unión se había enfrentado a un panorama político y económico en el que la conjunción de elementos de naturaleza tan dispar como los movimientos populistas fanáticamente antieuropeos o la creciente existencia de Estados miembros con actuaciones manifiestamente incompatibles con valores esenciales del ordenamiento jurídico comunitario están poniendo a prueba los resortes más íntimos de la Unión ${ }^{3}$ y, con ello, la propia idea de integración ${ }^{4}$.

1 Por muy apasionante que resulte la cuestión, no es momento de detenernos en esta sede en analizar los múltiples interrogantes jurídicos que plantea el artículo 50 TUE y a los que la Unión (y sus Estados miembros) habrán de ir dando respuestas en los próximos meses. Es muy probable que hasta el TJUE haya de enfrentarse, antes o después, con su interpretación. Nos permitiremos, empero, remitirnos al análisis que realizamos hace ya algunos meses a propósito de las dudas jurídicas que plantea la puesta en marcha del proceso de desconexión del Reino Unido a la luz de las previsiones recogidas en el artículo 50 TUE; «La Unión Europea ante el desafío del Brexit: de la decisión de los Jefes de Estado o Gobierno a la activación del procedimiento de retirada», Actualidad Jurídica Uría Menéndez, n. ${ }^{\circ} 43,2016$, pp. 7-23. Igualmente M. López EsCuDERO, «El incierto significado del Brexit», El Cronista del Estado Social y Democrático de Derecho 2016, n. ${ }^{\circ}$ 64, pp. 12-17; D. Sarmiento, «Y después del Brexit... ¿Qué?», El Cronista del Estado Social y Democrático de Derecho 2016, n. ${ }^{\circ}$ 64, pp. 42-47. Con carácter previo al Brexit, pero con interesantes reflexiones sobre la forma de proceder desde el punto de vista nacional en caso de ejercitar el derecho de retirada, véase la contribución de M. URREA CORRES, «La retirada de los Estados de la Unión en la Constitución europea», en AAVV, «La contitucionalización del proceso de integración europeo», Escuela Diplomática-BOE, Madrid, 2005, pp.289-304

2 En concreto, dijo que «[n]uestra Unión Europea se encuentra, al menos en parte, en una crisis existencial» y añadía que «nunca antes había visto que hubiera tan pocas cosas en común entre nuestros Estados miembros (...): Nunca antes había visto tanta fragmentación, tan pocas cosas en común en nuestra Unión»; Discurso pronunciado el 14 de septiembre de 2016 ante el Parlamento Europeo («Discurso sobre el Estado de la Unión, Hacia una Europa mejor: una Europa que proteja, empodere y vele por la seguridad»); disponible en http://europa.eu/rapid/ press-release_SPEECH-16-3043_es.htm. De cara al futuro de la Unión véase el Libro Blanco sobre el futuro de Europa, presentado por la Comisión el 1 de marzo de 2017, en el que los cinco escenarios que plantea se incluyen los de limitar la Unión a «solo el mercado común» (pp. 18-19) o el de «hacer menos pero más eficiente» (pp. 22-23)

3 Difícilmente pueden pasar inadvertidas en una revista fuertemente comprometida con los valores mencionados por el artículo 2 TUE, como es Teoría y Realidad Constitucional, las preocupantes consecuencias que se derivan, por ejemplo, de las conclusiones que algunos recientes informes de la Comisión de Venecia están poniendo de manifiesto en relación con determinados Estados miembros de la Unión. Mención especial, por su particular gravedad, merece la situación creada en Polonia, donde la actuación del nuevo Gobierno respecto al Tribunal Constitucional ha merecido uno de sus informes más duros y contundentes; véase VENICE Commission: Opinion on Amendments to the Act of 25 June 2015 on the Constitutional Tribunal on Poland, Opinion no. 833/2015, de 11 de marzo de 2016. Pero no puede tampoco olvidarse que no es el único caso, existiendo también algunas actuaciones en otros Estados que, aun sin haber sido objeto de escrutinio por la Comisión de Venecia, resultan realmente muy preocupantes.

4 De hecho, algún autor se ha referido de manera bastante gráfica a las 'siete plagas' que azotan actualmente a la Unión, «in which seven plagues have descended on the European Union: the banking crisis, the virtual collapse on th Greek Gouverment, the Ukraine crisis, the civil war in Syria, the refugee crisis, the effects of climate change, and the threat of a Brexit»; E. H. BALlin, «Europe: 'Coalescence in Diversity'», Asser Research Paper 2016, n. 4; publicado antes en neerlandés en la revista Nederlands Juristenblad 2016. 
Por otro lado, ya más íntimamente relacionada con el tema objeto de este trabajo, la segunda cuestión previa, que resulta imprescindible en el estudio del tribunal internacional con más amplias competencias, es la que se refiere a su relación (jurisprudencial) con los otros actores judiciales de constitucionalidad existentes en el ámbito territorial en el que se desarrolla su jurisdicción. Desde el momento en que el TJUE consigue revestirse de una dimensión manifiestamente constitucional $^{5}$, resulta irremediable el contacto $-\mathrm{y}$, antes o después, también el conflicto- con el resto de tribunales que cuentan también con una dimensión constitucional. En primer término, ello ha quedado patente desde las más tempranas fases del proceso de integración europea en las relaciones que el TJUE entabló con los Tribunales Constitucionales de los Estados miembros; muy en particular con el Bundesverfassungsgericht alemán, especialmente cuando se trataba de lograr la aceptación del capital principio comunitario de primacía del Derecho del Unión en caso de colisión con el Derecho de los Estados miembros, incluidas las disposiciones de rango constitucional. Pero en etapas más contemporáneas también se ha puesto de manifiesto, en segundo término, en sus relaciones con el Tribunal Europeo de Derechos Humanos (TEDH). Su naturaleza de tribunal internacional nada impide que poco (o nada) tenga que ver con otros tribunales internacionales al uso, como es el Tribunal Internacional de Justicia, la Corte Penal Internacional o el Tribunal Internacional de Derecho del Mar. Fruto de una

5 A estas alturas del proceso de integración europea resulta baldío detenerse en consideraciones a propósito de si resulta pertinente referirse al TJUE como el Tribunal Constitucional de la Unión. A nuestro juicio, es evidente que la Unión y su ordenamiento, pese a su evidente germen iusinternacional (base constitutiva en tratados internacionales, vigencia del principio de atribución expresa de competencia, inexistencia evidente de una Kompetenz-Kompetenz y papel de los Estados como Herren der Verträge o 'dueños y señores y de los tratados) están revestidos de otros elementos muy relevantes que únicamente pueden explicarse desde paradigmas de naturaleza netamente constitucional (entramado institucional basado en checks and balances desconocidos en otras organizaciones internacionales, vasta atribución de competencias en materias íntimamente ligadas al concepto de soberanía, papel del individuo como destinatario directo de derechos y obligaciones, existencia de un estatuto de ciudadanía europea, primacía y eficacia directa de sus normas, responsabilidad del Estado por incumplimiento del Derecho de la Unión, etc.). Es más, a nuestro entender, existen caracteres de la Unión y de su ordenamiento jurídico que resultan de inspiración inconfundiblemente federal, como hemos tratado de mostrar en diversos trabajos anteriores, especialmente en El federalismo supranacional — ¿un nuevo modelo para la Unión Europea?, Consejo Vasco del Movimiento Europeo, Vitoria, 2003.

Así las cosas, la vieja afirmación del propio TJUE de considerar los tratados constitutivos como la 'Carta constitucional' de la comunidad de Derecho que es la Unión encierra muy inteligentemente la aspiración de constitucionalidad del Tribunal de Justicia como Alto Tribunal de la Unión, cuya competencia, no lo olvidemos, la comparte con los tribunales de los Estados miembros, constituyendo una suerte de Poder Judicial de la Unión en el que quedan imbricados los jueces nacionales y los jueces de la Unión. A este respecto, pese al tiempo transcurrido desde su elaboración, siguen resultando referencia doctrinal obligada las ponderadas y clarividentes aportaciones realizadas por el juez español que más altas funciones ha ocupado en el TJUE; Gil Carlos RODRÍGUEZ IGLESIAS, «Der Gerichtshof der Europäsichen Gemeinschaften als Verfassungsgericht», Europarecht 1992, pp. 225-245; ib.: La dimensión constitucional del Derecho Comunitario europeo - Discurso de ingreso como académico honorario en la Academia Asturiana de Jurisprudencia, Oviedo, 1998; ib. y J. BAQUERO, «Funciones constitucionales del Tribunal de Justicia de la Unión Europea», Fundamentos-Cuadernos Monográficos de Teoría del Estado, Derecho Público e Historia constitucional, 2006, n. ${ }^{\circ}$ 4, pp. 291-346. Igualmente, véase A. Rosas, «The National Judge as EU Judge: Some Constitutional Observations», SMU Law Review 2014, vol. 67, pp. 717-727. 
actuación discreta, pero ininterrumpida, y de una jurisprudencia acumulada, que configura todo un compendio jurisdiccional en materia de derechos humanos, el TEDH ha ganado una posición protagonista en el ámbito europeo, difícilmente discutible por mucho que sea arduo ocultar en este momento las deficiencias obvias que también padece este tribunal (y, con ello, a veces también su jurisprudencia). Pero, en todo caso, de manera paralela a las conceptualizaciones del Convenio Europeo por la protección de los Derechos Humanos y las libertades Públicas (CEDH) como una suerte de Constitución en materia de derechos humanos $^{6}$, el TEDH se ha ganado también su consideración constitucional 7 . Sus relaciones con el Alto Tribunal de la Unión han sido más discretas y alejadas de los focos del escrutinio jurídico, pero no menos intensas y, en ocasiones, conflictivas. De hecho, estas relaciones se han erigido en merecido centro de atención doctrinal con ocasión del fallido intento de adhesión de la UE al CEDH como consecuencia de la polémica posición sostenida por el TJUE en diciembre de $2014^{8}$.

De esta manera, en el ámbito de los derechos fundamentales, se ha ido configurando una suerte de triángulo judicial europeo, cuyos vértices (constitucionales) los conforman el TJUE, los Tribunales Constitucionales de los Estados miembros y

6 Véase E. A. Alkema, «The European Convention as a Constitution and its Court as a Constitutional Court», en P. Mahony/F. Matscher/H. Petzold/L. Widhaber (eds.), Protecting Human Rights: The European Perspective - Studies in Honour of R. Ryssdal, Carl Haymanns Verlag, Colonia, 2000, pp. 41-63; F. HofFMEISTER, «Die Europäische Menschenrechtskonvention als Grundrechtsverfassung und ihre Bedeutung in Deutschland», Der Staat 2001, vol. 40, pp. 349-381, especialmente pp. 353-354; C. WalTER, «Die Europäische Menschenrechtskonvention als Konstitutionalisierungsprozess», Zeitschrift für ausländisches öffentliches Recht und Völkerrecht 1999, vol. 59, pp. 961-981.

7 A este respecto, puede verse la reciente contribución de H. KELlER y D. KüHnE, «Zur Verfassungsgerichtsbarkeit des Europäischen Gerichtshofs für Menschenrechte», Zeitschrift für ausländisches öffentliches Recht und Völkerrecht 2016, vol. 76, pp. 245-307, quienes analizan esta consideración constitucional a partir de los mecanismos de control del TEDH en un contexto constituional - instituciones, procedimientos y proceso de toma de decisiones - (pp. 255-286), así como del papel y funciones que se atribuyen a este Tribunal en relación con el resto de instituciones del Consejo de Europa (pp. 286-292); de manera prudente señalan también los límites que tiene toda comparación del TEDH con un Tribunal Constitucional al uso como consecuencia de su papel subsidiario, su limitación a fijar estándares mínimos, la existencia de muy amplios márges de apreciación en manos de los Estados y la gran limitación de sus competencias (pp. 302-305).

De todas formas esta consideración constitucional del TEDH no resulta en absoluto novedosa, sino que se ha constatado desde hace décadas en contribuciones de muy dispar enfoque; véase, por ejemplo, G. COHEN-JoHATHAN, «La fonction quasi constitutionnelle de la Cour européenne des droits de l'homme, en AAVV, Renouveau du droit constitutionnel - Mélanges en l'bonneur de L. Favoreu, Dalloz, París, 2007, pp. 1127-1153, quien se refiere a una función cuasiconstitucional del tribunal; K. W. WEIDManN, Der Europäüsche Gerichtshof für Menschenrechte auf dem Weg zu einem europäischen Verfassungsgerichtshof, Frankfurt a. M., 1985, quien alcanza esta misma conclusión a partir de un análisis de la metodología y fundamentos teóricos en materia de derechos humanos que emplea este Tribunal en su jurisprudencia; igualmente L. WILDHABER, «Eine Verfassungsrechtliche Zukunft für den Europäischen Gerichtshof für Menschenrechte?», Europäische Grundrechte-Zeitschrift 2002, Vol. 21-23, pp. 569-574, quien detecta una Constitución in fieri (también publicado en inglés, "A Constitutional Future for the European Court of Human Rights», Human Rights Law Journal 2002, n. ${ }^{\circ} 23$, p. 16); o R. UERPMANN-WiTTZACK, «Völkerrechtliche Verfassungselemente», en A. vON BogdANDY (ed.), Europäisches Verfassungsrecht, Springer, 2. ${ }^{a}$ edl, Berlín, 2009, pp. 177-225, en particular pp. 199-201, para el que se puede hablar de una Cuasiconstitución de Derecho Internacional (völkerrechtliche Nevenverfassung).

8 Dictamen 2/2013, de 18 de diciembre de 2014, ECLI:UE:C:2014:2454. 
el TEDH. Surgen, pues, sobre el espacio europeo tres 'titanes judiciales' con un vocación, reconocida o no, de contar con la mal llamada 'última palabra' ${ }^{\text {. No es de }}$ extrañar, por tanto, que en tal estado de cosas resulte inexcusable recurrir a mecanismos de cooperación judicial efectiva para lograr en la práctica una convivencia jurisprudencial armónica entre los tres niveles constitucionales europeos en liza; tampoco es de extrañar que en este peculiar contexto europeo resulten particularmente atractivos conceptos jurídicos como los que aluden al 'diálogo judicial' para referirse a las relaciones entre tribunales con aspiración constitucional. De este modo, también resultará preciso considerar construcciones jurídicas novedosas para explicar el nuevo orden jurídico que se está configurando en el espacio europeo.

Así las cosas, al valorar el papel del TJUE como actor de la constitucionalidad, merece la pena dedicar atención particular al papel que este tribunal internacional juega en la actualidad en el diálogo judicial que se ha entablado con los Tribunales Constitucionales de los Estados miembros y con el TEDH. Comenzaremos, por ello, por señalar someramente la importancia que este diálogo cobra en el que podríamos denominar espacio jurídico europeo multinivel, especialmente en materia de derechos humanos (II). A partir de ahí, una vez se apunte el estado actual de la tradicional cuestión de las relaciones entre el TJUE y los Tribunales Constitucionales, que ya no se limita sólo al ámbito de los derechos humanos (III), estaremos en situación de adentrarnos por la senda de las candentes relaciones presentes entre el TJUE y el TEDH (IV). Ello nos conducirá, finalmente, a la personal conclusión de que, en estos momentos de la larga y paciente partida que está en juego, el TJUE ha movido inteligentemente sus fichas, si bien existe también algún pronunciamiento reciente que lamentablemente nos obligará a ofrecer una valoración crítica que empaña su tarea desarrollada hasta el momento (V).

\section{LA IMPORTANCIA DEL DIÁLOGO JUDICIAL EN EL ESPACIO JURÍDICO EUROPEO MULTINIVEL: LOS DERECHOS HUMANOS COMO BANCO DE PRUEBAS PARA EL TRIÁNGULO JUDICIAL CONSTITUCIONAL EUROPEO}

\section{El diálogo judicial como viejo concepto actualmente en boga}

A la hora de abordar cualquier manifestación de la cooperación no reglamentada entre tribunales nunca se incidirá suficientemente, como cuestión metodológica y conceptual previa, en el hecho de que todavía pervive cierta indeterminación dogmática. Existe controversia doctrinal incluso a propósito de

9 J. Diez-Hochleitner Rodríguez, «El derecho a la última palabra: ¿Tribunales Constitucionales o Tribunal de Justicia de la Unión?», en AAVV, Tribunal Constitucional y diálogo entre tribunales — XVIII Jornadas de la Asociación de Letrados del Tribunal Constitucional, Centro de Estudios Políticos y Constitucionales, Madrid, 2013, pp. 57-130. 
la cuestión terminológica: mientras en nuestro entorno más próximo parece imponerse la referencia a diálogo judicial ${ }^{10}-\mathrm{y}$, por nuestra parte, hemos utilizado ese concepto ya en anteriores acercamientos a la cuestión ${ }^{11} \_$, en el ámbito anglosajón o germánico se está optando por otras denominaciones alternativas ${ }^{12}$.

Sí nos parece evidente, en todo caso, que el actual florecimiento de este diálogo judicial es consecuencia inevitable de tres fenómenos fundamentales que concurren en el tiempo y en el espacio, a saber, la globalización (con el consiguiente crecimiento exponencial de las relaciones transnacionales y la internacionalización de los ordenamientos jurídicos nacionales), la tecnificación del contenido de los ordenamientos jurídicos (con la especialización inevitable de los operadores jurídicos y, por tanto, también de los mecanismos de resolución de controversias) y la llamada fragmentación del Derecho Internacional (con la correlativa proliferación de tribunales internacionales en el marco de los diferentes subsistemas del Derecho Internacional). La concurrencia (temporal y espacial) de

10 La doctrina francesa suele referirse de forma genérica a este fenomeno como de dialogue entre les juges, L. Potvin-Solis, «Le concept de dialogue entre les juges en Europe», en F. Lichìre, L. Potvin-Solis y A. RaYNOUARD (dirs.), Le dialogue entre les juges européens et nationaux: incantation ou realité? , Bruylant, Bruselas, 2004, p. 19.

11 En efecto, pese a su aludida indeterminación, seguimos considerando adecuada la denominación diálogo judicial y nos remitimos a las contribuciones de referencia de nuestra doctrina más reputada para diferenciar este diálogo de otros fenómenos, como la mera 'conversación judicial'. A este respecto nos sigue pareciendo imprescindible el trabajo de Rafael Bustos GisBerT, «XV Proposiciones generales para una teoría de los diálogos judiciales», Revista Española de Derecho Constitucional 2012, n. ${ }^{\circ}$ 95, pp. 13-63, especialmente pp. 17-21. Somos, en todo caso, perfectamente conscientes de que entre la concepción restringida que puedan tener al respecto autores como Giuseppe de VERGOTTINI (Más allá del diálogo entre tribunales — Comparación y relación entre jurisdicciones, Civitas, Madrid, 2010) y la concepción mucho más amplia y abierta, como la sostenida entre nosotros por Javier GARCiA RoCA, dista todo un abismo ( «El diálogo entre el Tribunal Europeo de Derechos Humanos y los tribunales constitucionales en la construcción del orden público europeo», Teoría y Realidad Constitucional 2012, n. ${ }^{\circ}$ 30, pp. 181-222). Por nuestra parte, nos remitimos al respecto a nuestra previa contribución «El diálogo judicial entre el TJUE y el TEDH: algo más que el derecho a la última palabra en el triángulo judicial europeo», en AAVV, Tribunal Constitucional y diálogo entre tribunales - XVIII Jornadas de la Asociación de Letrados del Tribunal Constitucional, Centro de Estudios Políticos y Constitucionales, Madrid, 2013, pp. 161-208. Previamente habíamos tratado la cuestión de manera más general en «Viejos y nuevos problemas en el espacio europeo de los derechos humanos: Reflexiones a propósito de la necesaria cooperación judicial efectiva entre el TJUE y el TEDH», en M. Aznar Gómez/J. Cardona Llorens et al. (eds.), Estudios de Derecho Internacional y de Derecho Europeo en homenaje al profesor Manuel Pérez González, Tirant lo Blanch, Valencia, 2012, pp. 791-820.

12 En el entorno anglosajón se suele recurrir también a la noción de la transjudicial communication; A. M. Slaughter, «A Tipology of Transjudicial Communications», University of Richmond Review 1994-1995, vol. 29, pp. 99-137. A la vez, en la doctrina alemana existe un acercamiento a esta cuestión desde la perspectiva de concurrencia judicial (Rechtsprechungskonkurrenz); C. EndERs: «Offene Staatlichkeit unter Souveranitätsvorbehalt — oder: Vom Kampf der Rechtsordnungen nach Maastricht», en R. Grawer, B. SCHLINK, R. Wahl y J. Wieland (eds.), Offene Staatlichkeit - Festschrift für E. W. Böckenförde zum 65 Geburtstag, 1995, pp. 29-49, en particular p. 43. En cierto sentido, deja traslucir una idea de potencial conflicto entre los diferentes tribunales en juego; S. OETER, «Rechtsprechungskonkurrenz zwischen nationalen Verfassungsgerichten, Europäischen Gerichtshof und Europäischen Gerichtshof für Menschenrechte», Veröffenlichungen der Vereinigung der Deutschen Staatsrechtslehrer, 2007, n. ${ }^{\circ}$ 66, pp. 361-388, en p. 362. Incluso existen autores que esta idea de potencial conflicto, resulta, en el fondo, como algo «estructuralmente inevitable»; F. MERLI, Rechtsprechungskonkurrenz zwischen nationalen Verfassungsgerichten, Europäischen Gerichtshof und Europäischen Gerichtshof für Menschenrechte, Veröffenlichungen der Vereinigung der Deutschen Staatsrechtslehrer, 2007, n. ${ }^{\circ} 66$, pp. 392-419, en p. 393. 
estos tres fenómenos hacen inevitable no sólo el diálogo judicial aquí tratado, sino también el florecimiento de las técnicas del Derecho Comparado ${ }^{13}$ y el desarrollo de mecanismos reglados de cooperación judicial internacional, sea entre jueces de diferentes Estados a través de convenios de asistencia judicial ${ }^{14}$ o sea entre jueces de un Estado y el Tribunal de una organización internacional, como ocurre con la bien conocida cuestión prejudicial en la UE (art. 267 TFUE) ${ }^{15}$, pero también es el caso, más recientemente, de la cooperación prevista en el Protocolo 16 entre los más altos tribunales nacionales y el $\mathrm{TEDH}^{16}$.

Sin embargo, aunque los tres fenómenos recién aludidos son de carácter universal y ciertamente existen manifestaciones con similitudes notables en otros ámbitos regionales como el americano ${ }^{17}$, ha sido el continente europeo donde se

13 Véase, por ejemplo, J. García RocA, «El desarrollo de la comparación jurídica como ciencia y como materia en la enseñanza en España», Revista General de Derecho Público Comparado 2014, n. ${ }^{\circ} 14$, (www. iustel.com). Igualmente, A. vON BoGDANDY, «La transformación del Derecho europeo: el concepto reformado y su búsqueda de la comparación», Revista de Derecho Comunitario Europeo 2016, n. ${ }^{\circ}$ 54, pp. 441-471.

14 En el plano del Derecho Internacional son cada vez más abundantes los convenios bilaterales sobre asistencia y cooperación jurídica internacional, resultando ya tarea habitual (para los jueces y para la autoridad central, situada normalmente en nuestro caso en el Ministerio de Justicia). Amén de que, en el plano del Derecho de la Unión, el mecanismo de la euroorden ha supuesto una auténtica revolución en las relaciones entre jueces penales europeos en relación con la lista de delitos recogida en el anexo de la Decisión Marco 2002/584/ JAI del Consejo, de 13 de junio de 2002 (DOUE L 190 de 18 de julio de 2002, pp. 1-20).

15 A estas alturas no resulta ya menester subrayar el papel protagonista que la cuestión prejudicial ha tenido en el proceso de integración europea. Como bien ha subrayado el propio TJUE, la cuestión prejudicial tiene una importancia capital para preservar el carácter comunitario del Derecho instituido por los tratados constitutivos mediante «una cooperación directa entre el Tribunal de Justicia y los órganos jurisdiccionales nacionales en cuyo marco estos últimos participan de forma estrecha en la correcta aplicación y en la interpretación uniforme del Derecho de la Unión así como en la tutela de los derechos conferidos a los particulares por ese ordenamiento jurídico»; Dictamen 1/09, de 8 de marzo de 2011, ECLI: EU:C:123. Sí podría recordarse, en todo caso, las potencialidades que aún sigue manteniendo en la actualidad para la consolidación y efectividad del ordenamiento jurídico de la Unión. Salvo excepciones, los principales pronunciamientos constitucionales del TJUE siguen procediendo de consultas de los órganos jurisdiccionales nacionales, habiendo cobrado en este momento particular relevancia las planteadas por los Tribunales Constitucional nacionales; vid. infra, III. Véanse, a título de ejemplo, las reflexiones de T. vON DANwiTz, «Le dialogue de juge à juge — Considérations sur les devoirs réciproques des juges dans le cadre da la coopération juridictionnelle instaur'par l'article 267 du TFUE», en La Cour de justice de l'Union européenne sous la présidence de Vassilios Skouris (2003-2015) - Liber amicorum Vassiolios Skouris, Bruylant, Bruselas, 2015, pp. 713-725.

16 Protocolo n. ${ }^{\circ}$ 16, CETS No. 214. Su entrada en vigor requiere de 10 ratificaciones, existiendo en el momento de cerrar este trabajo tan sólo 6, siendo tres de ellas de Estados miembros de la Unión (Eslovenia, Finlandia y Lituania). Véase, por ejemplo, L. M. López Guerra, «Los protocolos de reforma n. ${ }^{\circ} 15$ y 16 al Convenio Europeo de Derechos Humanos», Revista Española de Derecho Europeo 2014, n. ${ }^{\circ}$ 49, pp. 11-29.

17 No cabe duda que el sistema interamericano probablemente reclama por nuestra parte mayor atención doctrinal de la que le hemos dedicado hasta el momento. Existe, de hecho, un interesante (y ambicioso) acercamiento abanderado por el Instituto Max Planck de Heidelberg, desde la perspectiva de la creacion de un Ius Constitutionale Commune en América Latina, digno de atento seguimiento. Véase, entre otros, A. vON Bogdandy, H. Fix-Fierro y M. Morales Antoniazzi (coords.), Ius Constitutionale Commune en América Latina: Riesgos y Desafíos, Mexico, 2014; A. von BogDAndy, «Ius Constitutionale Commune en América Latina: Beobachtungen zu einem transformatorischen Ansatz demokratischer Verfassungsstaatlichkeit», Zeitschrift für Ausländisches Öffentliches Recht und Völkerrecht 2015, vol. 75, pp. 345-381; ib.: «Ius Constitutionale Commune en América Latina: una mirada a un constitucionalismo transformador», Revista Derecho del Estado 2015, vol., 34, pp. 3-50. Un análisis sistemático de la jurisprudencia de la Corte Interamericana se 
han forjado los mecanismos de cooperación judicial más notables y, por lo que aquí más interesa, también de diálogo judicial.

\section{El espacio jurídico europeo multinivel como escenario óptimo para ensayar el diálogo judicial}

En efecto, en el continente europeo se ha dado en las últimas décadas una convergencia de los procesos de integración europea (UE) y de protección jurídica internacional de los derechos humanos (Consejo de Europa) que han creado una nueva realidad jurídica. Paralelamente, asistimos a un proceso de 'aperturismo' de los sistemas jurídicos ${ }^{18}$ — , así como a una convergencia entre ordenamientos ${ }^{19}$ en la que los paradigmas tradicionales del Derecho Internacional resultan cada vez más matizados por el $\mathrm{TJUE}^{20}$. Precisamente por ello el concepto de espacio jurídico, de tradición probada en el ámbito germánico (Rechtsraum), resulta particularmente útil para afrontar el acercamiento dogmático a esa nueva realidad jurídica $^{21}$. A la vez, en este contexto dogmático cambiante, las aproximaciones desde los paradigmas del 'pluralismo constitucional'22 y el constitucionalismo multinivel ${ }^{23}$ resultan particularmente atractivos $y$, aunque probablemente aún

encuentra en L. Burgorgue-Larsen y A. Úbeda De Torres, The Interamerican Court of Human Rights Case Law and Commentary, Oxford University Press, Oxford, 2011.

18 Esto no es, en realidad, un proceso exclusivo de Europa, como bien lo muestra, por ejemplo, L. BuRGORGUE-LARSEN, «El aperturismo. La técnica de interpretación 'reina' de los tratados regionales de protección de los derechos humanos», Revista Vasca de Administración Pública 2015, n. ${ }^{\circ} 103$, pp. 97-130 (traducido por D. Marinas SuÁrez).

19 Véase G. Martinico y O. Pollicino, The Interaction between Europe's Legal Systems - Judicial Dialogue and the Creation of Supranational Laws, Edward Elgar, Cheltenham-Northampton, 2014.

20 Véase, sin ánimo exhaustivo, J. Odermatr, «The use of International Treaty Law by the Court of Justice of the European Law», Cambridge Yearbook of European Legal Studies 2015, vol. 17, pp. 121-144.

21 Probablemente el proyecto más ambicioso derivado de esta concepción del espacio jurídico europeo (Europäischer Rechtsraum) es el que también está afrontando el Instituto Max Planck de Heidelberg a través de la publicación de una magna obra en la editoria muniquesa Beck (hasta ahora seis volúmenes, estando en preparación el séptimo) con el título Ius Publicum Europaeum. Una interesante referencia a la conformación del espacio jurídico europeo se encuentra en A. vON BOGDANDY, «Prinzipien der Rechtsfortbildung im europäischen Rechtsraum - Überlegungen zum Lissabon-Urteil des BVerfG», Neue Juristische Wochenschrift 2010, n. ${ }^{\text {os }} 1-2$, pp. 1-5, especialmente pp. 1-2.

22 Este acercamiento se inició a finales de la década de los noventa del siglo pasado de la mano de $\mathrm{N}$. McCornick, «Beyond the Sovereign State», Modern Law Review 1993, pp. 1-23; ib., «The Maastricht-Urteil: Sovereignty Now», European Law Journal 1995, pp. 259-266. Posteriormente fue seguido por otros autores, pudiéndose destacar las contribuciones de N. WALKER, «The Idea of Constitutional Pluralism», Modern Law Review 2002, n. ${ }^{\circ}$ 65, p. 317; M. P. MAduro, "Contrapunctual Law: Europe's Constitutional Pluralism in Action", en N. Walker (ed.), Sovereignty in Transition, 2003, S. 501-537; Julio Baquero: «The Legacy of the Maastricht-Urteil and the Pluralist Movement», European Law Journal 2008, pp. 389-422.

23 Ingold PERNICE ha sido probablemente el autor al que más claramente se le puede atribuir este acercamiento. Véase, como contribución básica en la materia, «Multilevel Constitutionalism in the european Union», European Law Review 2002, pp. 511-529. Entre sus últimas aportaciones, "The Treaty of Lisbon: Multilevel Constitutionalism in action», Columbia Journal of European Law 2009, pp. 349-407. Véase, 
insuficientes en sí mismos, aportan enfoques útiles para conceptualizar adecuadamente la nueva realidad jurídica; existen, con todo, otros muchos acercamientos, que oscilan entre los más clásicos, como por ejemplo el de la asociación de Estados (Staatenverbund) ${ }^{24}$, y la Constitución total (die totale Verfassung) ${ }^{25}$.

A partir de ese concepto de espacio jurídico y de las nuevas aproximaciones pluralistas y multinivel, bien puede afirmarse, con autores como Laurence BorGORGUE-LARSE, que el diálogo judicial al que aquí nos estamos refiriendo ha servido, en cierto sentido, para ir configurando lo que se ha dado en denominar un Derecho Constitucional europeo ${ }^{26}$; o como recientemente ha escrito Armin voN BogDANDY, un Derecho Europeo que engloba el Derecho de la UE y los instru-

igualmente, Armin von Bogdandy, «Bird's Eye View on the Science of European Law», European Law Journal 2000, p. 208, especialmente pp. 226-227.

24 Esta concepción, muy ligada al Tribunal Constitucional alemán, ha sido defendida en la docrita por P. KIRCHHOF, «Die rechtliche Natur der Europäischen Union als Staatenverbund», en A. vON BogDANDY y BAST (eds.), Europäisches Verfassungsrecht - Theoretische und dogmatische Grundzüge, 2. ed., Springer, Berlín, 2009, pp. 893-929, especialmente pp. 904-909.

25 No obstante, existen otros acercamientos a la teoría constitucional desde la perspectiva del Derecho Internacional que también tienen su interés. Así, por ejemplo, se habla de la contraposición entre el 'Estado total' (der totale Staat) de Carl Schmitt («Die Wendung zum totalem Staat», Europäsiche Revue 1931, vol. 7, pp. 241 y ss.) y la 'Constitución total' (die totale Verfassung), de la que habla por ejemplo M. Kumm («Who Is Afraid of the Total Constitution? Constitutional Rights as Principles and the Constitutionalization of Private Law», German Law Journal 2006, vol. 7, pp. 341-370). Igualmente, sobre la base del llamado constitucionalismo social (der gesellschaftliche Konstitutionalismus) de David ScIULLI, se han desarrollado diferentes posibles concepciones de un denominado pluralismo constitucional transnacional (transnationaler Verfassungspluralismus; G. Teubner, «Transnationaler Verfassungspluralismus: Neun Variationen über ein Thema von David Sciulli», Zeitschrift für ausländisches öffentliches Recht und Völkerrecht 2016, vol. 76, pp. 661-685. A partir de esta doctrina de Sciulli, el autor (profesor emérito de Sociología Jurídica), desarrolla nueve posibles variaciones en torno a tres grupos de conceptos básicos derivados de las diferentes críticas al pensamiento constitucional tradicional de Constitución centrada en la noción de Estado-nación. Entre ellas, por lo que al Derecho Internacional concierne más directamente, destaca la idea de una Constitución global (Globalverfassung) en la que distingue las variantes de una Constitución social holística (Holistische Gesellschaftverfassung) y una Constitución como imaginario colectivo (Verfassung als kollektive Imagination); loc. cit., pp. 674-677. Estas posiciones conectan, a su vez, con aquellas corrientes del Derecho Internacional y la Filosofía del Derecho que, a partir de concepciones cosmopolitas (más idealistas que reales) están sosteniendo la constatación de una constitucionalización del Derecho Internacional que podría sedimentar en una única Constitución para toda la sociedad internacional; cfr. B. FAssbener, «We the Peoples of the United Nations: Constituent Power and Constitutional Form in Internationa Law», en N. WALKer/M. Loughlin (eds.), The Paradox of Constitutionalism: Constituent Power and Costitutional Form, Oxford University Press, Oxford, 2007, pp. 269 y ss. (cap. 14), especialmente pp. 281-283. En todo caso, sobre el proceso de constitucionalización del Derecho Internacional, véase A. vON BOGDANDY, "Constitutionalism in International Law: Comment on a Proposal from Germany», Harvard International Law Journal 2006, vol. 47, pp. 223-242, quien expone la visión de un sector relevante de la doctrina alemana, que lo personifica en las contribuciones de Christian Toмuschat, especialmente en relación con cuestiones como la normatividad del Derecho Internacional, el papel del Estado o la legitimidad del Derecho Internacional; E. de WET: «The Emergence of International and Regional Value Systems as a Manifestation of the Emergin International Constitutional Order», Leiden Journal of International Law 2006, vol. 19, pp. 611-632; J. Klabbers/A. Peters/G. Ulfstein, The Constitutionalization of International Law, Oxford University Press, Oxford, 2009.

26 «La formación de un derecho constitucional europeo a través del diálogo judicial», en J. I. UGARtemendía y G. Jáuregue Berenciartu (coords.), Derecho Constitucional Europeo - Actas del VII Congreso de de la Asociación de constitucionalistas de España, Tirant lo Blanch, Valencia, 2011, pp. 41-76; ib., «Pour une 
mentos internacionales que lo complementan, así como el CEDH, las normas nacionales que la transponen y aplican y el Derecho comparado europeo ${ }^{27}$. Sea como fuere, el caso es que en este peculiar e innovador constitucionalismo europeo es precisamente el ámbito de los derechos humanos el que mejor se presta a erigirse en banco de pruebas del innovador concepto de espacio jurídico europeo; y también del diálogo judicial entre sus tres tribunales de naturaleza constitucional.

\section{Los derechos humanos como ámbito por antonomasia del diálogo judicial europeo}

En efecto, el campo de los derechos fundamentales constituye la manifestación más evidente de la relevancia del nuevo constitucionalismo contemporáneo para el individuo en el mencionado espacio jurídico europeo ${ }^{28}$ —en parte, también del iusinternacionalismo ${ }^{29}$ — y es reflejo paralelo del principal límite negativo a la actuación de los poderes públicos (sea del Estado o sea de una organización internacional supranacional como la UE). Encarna, así, el ámbito material más propicio para poner en práctica el aludido diálogo judicial ${ }^{30}$.

Es más, en el ámbito europeo, este diálogo judicial en materia de derechos humanos ha tenido como una de sus consecuencias más sobresalientes el recíproco enriquecimiento de los tres ordenamientos jurídicos en liza. En el plano de los Estados miembros, ha permitido amortiguar los efectos que el proceso de atribución de competencias a la Unión ha tenido sobre sus estructuras constitucionales internas; en el caso de la Unión, ha servido para retroalimentar e impulsar el

approche dialoguique du droit constitutionnel européen», AAVV, Mélanges Constantinesco, Bruylant, Bruselas, 2015, pp. 635-665.

27 «La transformación del Derecho Europeo: el concepto reformado y su búsqueda de la comparación», Revista de Derecho Comunitario Europeo 2016, vol. 54, pp. 441-471.

28 Véase, por ejemplo, el reciente trabajo de A. Carmona Contreras, «El espacio europeo de los derechos fundamentales: De la Carta a las Constituciones nacionales», Revista Española de Derecho Constitucional 2016, n. ${ }^{\circ} 107$, pp. 13-40.

29 J. CARDOna Llorens, «Hacia la configuración de un 'sistema' de protección de los derechos humanos de las Naciones Unidas», en Cursos de Derecho Internacional y Relaciones Internacionales de Vitoria-Gasteiz, Thomson-Reuters, Cizur Menor, 2016, pp. 135-176.

30 Existen, sin duda, otros ámbitos materiales que también suministran interesantes expresiones novedosas de diálogo judicial, como son por ejemplo el campo de la protección de las inversiones, con el frondoso campo del arbitraje florecido a su arropo, o el del fecundo Derecho de la Competencia, que está dando lugar a todo un cuerpo jurídico transnacional cuya concepción final resulta ser una curiosa mezcla de aspectos inspirados en la Shipping Act norteamericana, la doctrina del Bundeskartelamt alemán y el indudable papel catalizador de la Comisión de la UE (con el respaldo jurisprudencial del TJUE). Incluso la lucha contra los más graves crímenes internacionales (genocidio, lesa humanidad, crímenes de guerra, agresión...) dan también buen ejemplo de ello, a través de la actuación de la Corte Penal Internacional y la correlativa exigencia de cooperación de los jueces nacionales, a la par que también genera normas obligatorias indisponibles para los Estados. Pero nadie podrá poner en duda que los derechos humanos constituyen el más evidente y desarrollado campo para el diálogo judicial aquí tratado. 
propio proceso de integración ${ }^{31}$; y, desde la perspectiva del TEDH, ha actuado como instrumento para reforzar su papel constitucional como depositario del control judicial último (a los Estados y también a la Unión) en materia de derechos humanos. A la postre, bien podría decirse que hemos asistido a una constitucionalización de la UE a la par de una europeización (e internacionalización) paralela de las Constituciones nacionales.

\section{LA RELACIÓN ENTRE EL TJUE Y LOS TRIBUNALES CONSTITUCIONALES NACIONALES: UNA HISTORIA DE AMBICIONES COMUNES RAZONABLEMENTE BIEN ENCAUZADA}

\section{El protagonismo actual de la identidad constitucional}

En este contexto, el primer y principal banco de pruebas del diálogo judicial sobre el espacio jurídico europeo de los derechos humanos ha sido el entablado entre el TJUE y los Tribunales Constitucionales de los Estados miembros. Sirvió, en primer término, para que éstos marcaran las reglas de juego necesarias para aceptar en el ámbito constitucional nacional las severas consecuencias jurídicas derivadas del ordenamiento jurídico de la Unión (especialmente el principio de primacía). En este diálogo, sin menoscabo del papel también relevante jugado por otros tribunales, ha sido el Bundesverfassungsgericht alemán el que ha ejercido siempre un cierto papel de 'faro jurídico' para el resto de Tribunales Constitucionales, a la vez que ha mantenido también un permanente 'tira y afloja' con el $\mathrm{TJUE}^{32}$. De hecho, ha mostrado con frecuencia una cierta 'rebeldía' frente a unas reglas comunitarias que les han ido alejando progresivamente de la 'última palabra’ en el cada vez más amplio ámbito de competencias atribuidas a la Unión. Pero nunca hasta ahora se ha pasado de la fase de amagar. Así, amagó muy seriamente en Solange $I^{33}$, pero, tras la consideración de los derechos humanos procedentes de las tradiciones constitucionales comunes de los Estados miembros como principios generales del Derecho de la Unión ${ }^{34}$, se corrigió en Solange II $^{35}$ y

31 Cfr. L. Scheeck, «The Relationship between the European Courts and Integration through Human Rights», Zeitschrift für Ausländisches Öffentliches Recht und Völkerrecht 2005, vol. 65, pp. 837-885.

32 Esta cuestión la analizamos con más detalle en «La contribución del Tribunal Constitucional alemán al Derecho comunitario europeo: el permanente 'tira y afloja' con el Tribunal de Justicia de la UE», en S. Ripoll Carulla y J. I. Ugartemendía (coords.), España ante los tribunales internacionales europeos. Cuestiones de política judicial, IVAP, Oñate, 2008, pp. 175-197.

33 BVerfGE 37, 271, especialmente apdo. 56.

34 TJUE sentencia de 17 de diciembre de 1970, Internationale Handelsgesellschaft, ECLI: EU: C: 1970: 114 .

35 BVerfGE 73, 339, especialmente apdo. 132. 
se confirmó en el asunto Bananas ${ }^{36}$. Logró, así, forzar al propio TJUE a responder a sus exigencias de protección suficiente de los mismos en el ámbito de la Unión ${ }^{37}$.

En realidad, este diálogo entre el TJUE y los Tribunales Constitucionales nacionales se ha trasladado ahora al no menos apasionante debate sobre los (posibles) límites a la atribución de competencias de los Estados a la Unión y, a través de ello, su plasmación en el indeterminado concepto de 'identidad constitucional'. Más en concreto, el Tribunal Constitucional alemán se planteó en su pronunciamiento sobre el Tratado de Lisboa $^{38}$, retomando la espita abierta por la anterior sentencia sobre el Tratado de Maastricht ${ }^{39}$, la difícil cuestión a propósito de si un Tribunal Constitucional goza en casos extremos de competencia suficiente para conocer por sí mismo de una posible extralimitación competencial por parte de las instituciones de la Unión $^{40}$, esto es, la constatación de una actuación ultra vires de la Unión ${ }^{41}$.

Prima facie resulta obvio (y hasta ofensivamente elemental) que tal competencia recae en exclusiva en el TJUE (arts. 19.1 TUE y 251 a 281 TFUE). Mas el Tribunal Constitucional alemán planteó en su citada sentencia de 30 de junio de 2009, tras explayarse en pasajes ciertamente preocupantes desde la perspectiva del Derecho de la Unión ${ }^{42}$, una suerte de ‘órdago' al TJUE al establecer la existencia de

36 BVerfGE 102, 147.

37 En la actualidad, se platea precisamente la cuestión contraria, a saber, la de una Solange a la inversa para impedir que los tribunales de los Estados puedan reducir el nivel de protección de determinados derechos humanos; A. von Bogdandy, M. Kottmann, C. Antpöhler, J. Dickschen y S. Hentrei, «Reverse Solange: Protecting the essence of fundamental rights against EU Member States», Common Market Law Review 2012, vol. 49, pp. 489-519.

38 BVerfGE 123, 267.

39 BVerfGE 89, 155. En esta sentencia el Tribunal Constitucional alemán no emplea (todavía) expresamente el concepto de identidad constitucional, pero sí adelanta la existencia de determinados valores que, como es el caso del principio democrático, constituyen elementos esenciales de la Constitución alemana. Por lo demás, la sentencia deja todo un reguero de afirmaciones susceptibles de polémica desde la perspectiva del Derecho de la Unión.

$40 \mathrm{Ib}$., apdo. 240.

41 Sobre esta cuestión puede verse la reciente contribución de J. I. UGARTEMENDía ECEIZABARRENA, «El control de comunitariedad de las resoluciones judiciales y el límite de la identidad constitucional», Revista Española de Derecho Europeo 2016, n. ${ }^{\circ}$ 59, pp. 13-43. Igualmente, F. Balaguer Callejón, «Primato del diritto europeo e identità constituzionale nell'esperienza spagnola», en AAVV, 1 Controlimiti - Primato delle norme europee e difesa dei principio constituzionali, a cura di Alessandro Bernardi, Jovene Editore, Napoli, 2017, pp. 113-133.

42 Esta controvertida sentencia recogía con profusión el argumento suplementario de que el concepto de la estatalidad soberana alemana constituía un elemento necesario de la 'identidad constitucional', que en modo alguno podía ser eliminado por el proceso de integración europea (apdo. 216). Ahora bien, resulta curioso observar cómo la sentencia cita en no menos de 40 ocasiones el concepto de soberanía del Estado alemán, haciéndolo en los más variados contextos. A veces, lo hace para exigir que se garantice la soberanía del Estado nacional (souveräne Verfassungsstaatlichkeit) (apdo. 226). Otras para definir un concepto de Unión de Estados (Staatenverbund) en la que estos mantienen su carácter soberano (souverän bleibende Staaten) (apdo. 229) o para reiterar el ya conocido argumento de que la Ley Fundamental de Bonn no autoriza el ingreso de Alemania en un Estado federal en el que desapareciera el derecho de autodeterminación del pueblo alemán en la forma de la soberanía del Derecho Internacional de Alemania (die völkerrechtliche Souveranität Deutschlands) (apdo. 228). Por tanto, no puede sorprender tampoco la reiterada referencia al también bien querido concepto de los Estados como Herren der Verträge (apdos. 231, 235, 298, 334, etc.). 
límites a la atribución de competencias y arrogarse con una competencia propia de examen del Derecho de la Unión por actuación ultra vires ${ }^{43}$. De nuevo el Tribunal Constitucional alemán manifestó, así, cierta 'rebeldía' y amagó con no aceptar un elemento vital del Derecho de la Unión, si bien inmediatamente después de aquello no se pasó a mayores ni en el asunto de la Directiva de datos (Directiva 2006/24/ CE) ni en el posterior del EFSF. En el primero, el Tribunal Constitucional declaró inconstitucional el acto nacional de transposición, pero dejó a salvo al Directiva ${ }^{44}$; y en el segundo fijó la imposibilidad de limitar la autonomía presupuestaria del Bundestag por acuerdos que incluyan la responsabilidad financiera respecto a terceros Estados en los que no resulte posible calcular con facilidad el montante exacto, pero sin poner en tela de juicio la posibilidad de responsabilidad de fondo ${ }^{45}$.

En este ámbito, como ocurrió antes en materia de derechos humanos, de nuevo ha sido seguido, a mayor o menor distancia, por otros Tribunales Constitucionales. Piénsese que, sin ir más lejos, no muy diferente es la posición sostenida por nuestro Tribunal Constitucional en la Declaración 1/2004 al corregir el rumbo de la criticada Declaración $1 / 1992^{46}$. Así, una vez aclarada la dimensión material del artículo 93 de la Constitución y referirse metafóricamente a su función bisagra, estableció la existencia de límites materiales implícitos a la atribución de competencias operada a través del mencionado precepto constitucional, «que se traducen en el respeto de la soberanía del Estado, de nuestras estructuras constitucionales básicas y del sistema de valores y principios fundamentales consagrados en nuestra Constitución, en el que los derechos fundamentales adquieren sustantividad propia» ${ }^{47}$. Posiciones parecidas han sido mantenidas también,

43 A nuestro entender, como tuvimos ocasión de manifestar al analizar pormenorizadamente esta sentencia, el Tribunal Constitucional alemán hace desaparecer en su pronunciamiento cualquier atisbo de europeización y actualización de la teoría clásica alemana del Estado, con un enquistamiento excesivo en los conceptos de Estado y soberanía. A la vez, como ya había ocurrido en su previa sentencia sobre el Tratado de Maastricht, hace también gala de una consideración bastante miope y germanocéntrica del principio democrático, así como muestra una insistencia en el 'déficit democrático' de la Unión en el que quedó totalmente ausente cualquier atisbo de acercamiento europafreundlich al proceso de integración europea; «Órdago del Tribunal Constitucional alemán al proceso de integración europea (Algo más que una sentencia crítica con el Tratado de Lisboa)», Revista d'Estudis Autonomics i Federals 2011, n. ${ }^{\circ} 13$, pp. 97-145.

44 BVerfG, 1 BvR 256//08 de 2 de marzo de 2010, apdo. 218.

45 BVerfGE 129, 124

46 Declaración 1/1992, de 1 de julio de 1992. En ella se hacía referencia a la dimensión únicamente 'orgánico-procedimental' del artículo 93 de la Constitución.

47 Declaración 1/2004, de 13 de diciembre de 2004, FJ. 2 in fine. Las novedades y trascendencia de este importante pronunciamiento constitucional las analizamos in extenso en «Hacia una nueva concepción del artículo 93 de la Constitución: comentario a la Declaración 1/2004 del Tribunal Constitucional», Revista Española de Derecho Internacional 2005, vol. 57, pp. 799-818.

No parece momento ni lugar adecuados para mezclar estas reflexiones con el delicado tema de la deriva soberanista experimentada en los últimos años en Cataluña y la respuesta jurisprudencial que el Tribunal Constitucional ha ido dando a este fenómeno al que esta revista dedicó monográficamente su número 37 y al que por nuestra parte le hemos dedicado atención en nuestra contribución «Legal considerations regarding a hypothetical unilateral declaration of independence of Catalonia: a legally unfeasible political scenario» Spanish Yearbook of International Law 2015, n. ${ }^{\circ}$ 19, pp. 35-59. Pero, quizá, no esté de más recordar que en la 
con mayor o menor acierto, por otros Tribunales Constitucionales nacionales ${ }^{48}$, siendo, por ejemplo, el caso húngaro el más reciente ${ }^{49}$.

El problema, a la postre, radica en precisar los contornos precisos del concepto de 'identidad constitucional'. Esta noción, al margen del cierto margen de indeterminación intrínseca que le es propio ${ }^{50}$, exige la consideración de los elementos de individualidad o esencia propios de cada ordenamiento concreto ${ }^{51}$. En Alemania esta labor se ve notablemente facilitada por la existencia de una bien conocida cláusula de intangibilidad (Ewigkeitsgarantie), recogida en el artículo 79.3 de la Ley Fundamental de Bonn ${ }^{52}$. Pero su traslación mimética a ordenamientos jurídicos como el nuestro, que carecen de tal cláusula, resulta bastante más compleja y obliga a recurrir a conceptos menos precisos, como el de 'núcleo duro' de la Constitución.

respuesta jurisprudencial del Tribunal Constitucional al reto soberanista catalán se encuentran, de manera muy colateral, referencias a la cuestión de los límites de la reforma constitucional; no en vano es un tema que aflora en situaciones límite. Ciertamente ha establecido que «[t]odas y cada una de las determinaciones constitucionales son susceptibles de modificación», siempre que «el intento de su consecución efectiva se realice en el marco de los procedimientos de reforma de la Constitución» (STC 259/2015, de 2 de diciembre de 2015 , FJ 7). Pero ha añadido también un límite material al considerar que «el planteamiento de concepciones que pretendan modificar el fundamento mismo del orden constitucional tiene cabida en nuestro ordenamiento, siempre que no se prepare o defienda a través de una actividad que vulnere los principios democráticos, los derechos fundamentales o el resto de los mandatos constitucionales, y el intento de su consecución se realice en el marco de los procedimientos de reforma de la Constitución» (ib., FJ 7; STC 42/2014, de 25 de marzo de 2014, FJ 4) (cursiva añadida por nosotros).

48 Sobre la influencia del Tribunal Constitucional alemán en sus homólogos de Polonia y Hungría, vid. A. F. TAтham, Central European Constiututional Courts in the Face of EU Membership, Marinus Nijhoff, Leide-Boston, 2013.

49 El pasado 30 de noviembre de 2016 el Tribunal Constitucional de Hungría ha emitido un dictamen, a petición del Defensor del Pueblo de Hungría, a propósito de eventuales conflictos entre el Derecho de la UE y la Constitución húngara en materia de reubicación en otros Estados miembros de personas que solicitaron asilo en Italia y Grecia y permanecen en esos países. El Tribunal Constitucional ha establecido que «Hungría está sujeta tanto a la doctrina del TJUE como del Tribunal Constitucional, y en ningún caso se permitirá que se vulnere la soberanía de Hungría ni desafíe la identidad constitucional del país»; traducción propia del comunicado de prensa publicado el 30 de noviembre de 2016 por el Tribunal Constitucional húngaro. Por lo que aquí más interesa, el Tribunal Constitucional dictaminó que puede examinar si la aplicación de competencias contenidas en el párrafo 2 del artículo E) de la Ley Fundamental [equiparable a nuestro artículo 93 de la Constitución] vulnera o no la dignidad humana, los derechos fundamentales, la soberanía de Hungría o la identidad constitucional del país (párrafo final del Comunicado de prensa del Tribunal Constitucional húngaro).

50 Cfr., sobre la problemática conceptualización de esta noción de identidad constitucional, M. RosENFELD, «Constitutional Identity», en ib./A. SAJó (eds.), The Oxford Handbook of Comparative Constitutional Law 2012, pp. 756-776.

51 G. van der SCHYFF, «The Constitutional Relationship between the European Union and Its Member States: The Role of National Identity in Art. 4 para. 2 TEU», European Law Review 2002, vol. 27, pp. 563584, en p. 569-570; ib., «EU Member State Constitutional Identity: A Comparison of Germany and the Netherlands as Polar Opposites», Zeitschrift für ausländisches öffentlichtes Recht und Völkerrecht 2016, vol. 76, pp. 167-191, en p. 169.

52 A este respecto, resulta interesante la controversia surgida en la doctrina alemana a propósito de si el propio artículo 79.3 podría ser modificado mediante el mecanismo de reforma constitucional. A favor de esta posición, B.O. BRYDe, «Art. 79», en I. von MüNCH y P. KUnig (eds.), Grundgesetz — Kommentar, Beck Verlag, Munich, 6. ${ }^{\text {e }}$ ed., 2012, tomo 2, apdo. 27. En sentido contrario, J. IPSEN, Staatsrecht I — Staatsorganisationsrecht, Vahlen, 28. ${ }^{\text {a }}$ ed., Munich, 2016, p. 283 apdo. 1041. 
Sea como fuere, la realidad es este concepto que marca, en todo caso, la senda de las relaciones con el TJUE y, lo que es realmente relevante, a nuestro entender muestra a las claras una predisposición positiva de los Tribunales Constitucionales a continuar jugando el partido dentro del campo de juego fijado por los tratados constitutivos y, desde el Tratado de Lisboa, muy particularmente por el artículo 4.2 TUE ${ }^{53}$. En cierta forma, podría decirse, insistiendo en el símil, que las reglas del juego las han fijado los Estados a través de los tratados constitutivos, aunque ha dejado la tarea de árbitro al TJUE, bien que con el estricto y permanente escrutinio de los Tribunales Constitucionales nacionales.

\section{La normalización del uso de la cuestión prejudicial por los Tribunales Constitucionales nacionales}

Al final, más allá de la 'rebeldía' aparente mostrada por el Tribunal Constitucional alemán en los pronunciamientos citados en relación con el control ultra vires, conviene constatar que de nuevo todo ha quedado en amagos, ya que ha aceptado al final las reglas mínimas de la cooperación judicial (y el diálogo) con el TJUE. Así, en el asunto Honeywell el Tribunal Constitucional marcó claramente su 'declaración de intenciones' al respecto y dejó sentado que, antes de abordar el aludido posible control ultra vires, haría uso de la cuestión prejudicial ante el $\mathrm{TJUE}^{54}$. Y eso fue precisamente lo que ha ocurrido en el trascendental asunto Gauweiler. Así, el Tribunal Constitucional planteó al Tribunal de Justicia, con una formulación ciertamente ‘algo' subida de tono ${ }^{55}$, si el programa del Banco Central Europeo (BCE) de compra de títulos de deuda pública de los Estados

53 Sobre la base del precedente del artículo F. 1 TUE que introdujo el Tratado de Maastricht, los tratados constitutivos prevén expresamente la exigencia de que la Unión respete la identidad nacional de los Estados miembros, «inherente a las estructuras políticas y constitucionales de éstos, también en lo referente a la autonomía local y regional». Ello, desde la perspectiva de la Unión, encarna un límite evidente a su acción, mientras que, desde la perspectiva estatal, supone una vía de protección de la citada identidad constitucional de los Estados miembros en el sentido fijado por la jurisprudencia del Tribunal Constitucional alemán y en cierto sentido una suerte de límite a una concepción absoluta del principio de primacía del Derecho de la Unión; véase, por todos, A. vON Bogdandy y S. Schill, «Overcoming Absolute Primacy: Respect for National Identity under the Lisbon Treaty», Common Market Law Review 2011, vol. 48, pp. 1417-1454.

54 BVerfGE 126, 286, especialmente apdo. 60 y apartado b) del tenor primero de la decisión.

55 La cuestión prejudicial está redactada en unos términos que, en más de uno de sus apartados, traslucen una clara inclinación del Tribunal Constitucional alemán a considerar que la política monetaria del BCE pueda encarnar una violación del Derecho de la Unión; F.C. MAYer, «Rebels without a Cause? A Critical Analysis of the German Constitutional Court's OMT Reference», German Law Journal 2014, vol. 15, pp. 111146. Incluso un sector doctrinal ha hablado de una cierta arrogancia del Alto Tribunal alemán como consecuencia del tono empleado; C. Secondat/P.J. Goosens/D. Rotarod, «The German Constitutional Court's Decision about the European Central Bank's OMT Mechanism: A Masterpiece of Judicial Arrogance», European Policy Brief 2014, n. ${ }^{\circ} 30$ (abril de 2014). D. Murswiek: «ECB, ECJ, Democracy, and the Federal Constitutional Court: Notes on the Federal Constitutional Court's Referral Order from 14.1.2014», German Law Journal 2014, vol. 15, pp. 147-166. 
miembros en el mercado secundario (OMT) resultaba compatible con los tratados constitutivos, a lo que el TJUE respondió en sentido afirmativo ${ }^{56}$. Este pronunciamiento tampoco estuvo exento de atención crítica, ya que a cualquier lector atento difícilmente le podrá pasar por alto la ligereza con la que el TJUE resuelve la cuestión de la admisibilidad ${ }^{57}$; dada la naturaleza simplemente preparatoria del acto del BCE puesto en cuestión (un comunicado de prensa), las 'dificultades funcionales' de las que prudentemente hablaba el Abogado General Pedro Cruz Villalón en sus Conclusiones Generales ${ }^{58}$ eran ya de por sí un eufemismo que, a nuestro juicio, hubiera exigido una mayor atención del TJUE para justificar su desvío de la jurisprudencia anterior sobre la materia. Pero, por lo que aquí más interesa, el Tribunal Constitucional alemán aceptó el pronunciamiento del TJUE como intérprete último de los tratados constitutivos, aunque fuere no sin antes recrearse en una visible crítica ${ }^{59}$.

En el fondo, de nuevo, puede buscarse cierto paralelismo con la experiencia vivida por nuestro Tribunal Constitucional con ocasión del planteamiento de su primera cuestión prejudicial en el asunto Melloni ${ }^{60}$. Dejando de lado la ya infructuosa discusión sobre si el Alto Tribunal español escogió realmente el mejor caso para romper el hielo del reenvío prejudicial al Tribunal de Justicia ${ }^{61}$ y absteniéndose también del discutible hecho de que su sentencia final se haya fundado únicamente en el artículo 10.2 de la Constitución para justificar su cambio

56 TJUE sentencia de 16 de junio de 2015, C-62/14; ECLI:EU:C:2015:400. Esta sentencia ha de ser leída en conjunción con la dictada previamente en el asunto Pringle, ECLI: UE: C: 2012: 756. Véase, entre nosotros, la reciente contribución de D. SARMiento, «La sentencia Gauweiler (C-62/14) del Tribunal de Justicia de la Unión Europea, sobre el programa de compra de deuda pública por el Banco Central Europeo», Revista Española de Derecho Europeo 2016, n. ${ }^{\circ}$ 57, pp. 63-74. Igualmente, F. SANDER: «Case C-62/14 Gauweiler and others: The Limits of Monetary Policy in Light of the Outright Monetary Transactions (OMT) Program», Columbia Journal of European Law 2016, vol. 22, pp. 529-538.

57 Apdo. 20.

58 Apdos. 30 a 32.

59 BVerfG 2 BvR 2728 a 2731/13, 2BvE 13/13, sentencia de 21 de junio de 2016.

60 TJUE sentencia de 26 de febrero de 2013, ECLI:EU:C: 2013: 107. Esta sentencia ha recibido cierta crítica doctrinal. Véase, por ejemplo, C. IzQuierdo SANS, «Sobre lo que opina el TJ con relación a la definición del nivel de protección de un derecho fundamental por parte del legislador de la Unión. Comentario a la Sentencia del TJUE de 26 de febrero de 2013, Asunto Melloni, C-399/11», La Ley Unión Europea 2013, n. ${ }^{\circ}$ 75, pp. 29-36, especialmente pp. 33-36.

61 Efectivamente, en su momento levantó cierta polvareda doctrinal la cuestión de si nuestro Tribunal Constitucional había escogido el asunto más adecuado para dar el muy deseable paso de utilizar el mecanismo del artículo 262 TFUE en su Auto 86/2011, de 9 de junio. De hecho, en nuestra doctrina concurren tanto una posición muy favorable a la decisión del TC, como una posición bastante crítica al respecto. A favor de la primera perspectiva, véase, por ejemplo, P. Andrés SÁnEZ de SANTA María, «Un nuevo paso en el diálogo judicial europeo: el Tribunal Constitucional español recurre al reenvío prejudicial», en C. Fernández Liesa/C. Moreiro González/E. Menéndez (coords.), Libro homenaje a Dámaso Ruiz Jarabo, CGPJ-Universidad Carlos III, Madrid, 2011, pp. 189-214, especialmente p. 193; C. IZQUierdo SANS, loc. cit. (Sobre lo que opina el TJ...), nota 60, pp. 29-30. Por el contrario, en un sentido crítico, puede verse, v.gr., el voto particular del magistrado PÉrez Tremps; igualmente M. RevengA, «Rectificar preguntando. El Tribunal Constitucional acude al Tribunal de Justicia», Revista Española de Derecho Europeo 2012, num. 41, pp. 135-150. 
jurisprudencial ${ }^{62}$, el elemento esencial es que nuestro Tribunal Constitucional ha terminado por aceptar para sí la vía del artículo 267 TFUE.

En suma, los Tribunales Constitucionales están en curso de normalizar el uso de la cuestión prejudicial como mecanismo institucionalizado para canalizar la cooperación judicial constitucional entre dos de los vértices fundamentales del triángulo judicial europeo; lástima, por cierto, que no haya seguido este mismo camino el Tribunal Supremo del Reino Unido al conocer el asunto del Brexit ${ }^{63}$. Se da, así, un primer paso decisivo que veremos si se ve completado con la cooperación prevista en el Protocolo 16 (entre los más altos tribunales nacionales y el TEDH) y el proyectado mecanismo de pronunciamiento previo del TJUE en caso de que, de materializarse en algún momento la adhesión de la UE al CEDH, el TEDH conociera de algún caso que afectase al Derecho de la UE sin que hubiera recaído previamente pronunciamiento del TJUE ${ }^{64}$.

\section{Un balance de diálogo judicial razonablemente positivo}

De cualquier forma, por lo que ahora interesa, visto con cierta perspectiva histórica y dejando de lado los detalles, bien puede considerarse que el diálogo judicial entre el TJUE y los Tribunales Constitucionales se ha cerrado con un

62 En este mismo sentido crítico, puede verse en la doctrina la, a nuestro entender, convincente contribución de J. I. Ugartemendía y S. Ripol Carulla, «Del recato de la jurisprudencia del Tribunal Constitucional sobre la tutela judicial de los DFUE y de las cuestiones y problemas asociados a la misma (a propósito de la STC 26/2014, de 13 de febrero)», Revista Española de Derecho Europeo 2014, n. ${ }^{\circ}$ 50, pp. 105149. Menos crítica, aunque reconociendo el 'minimalismo constitucional' y la parquedad argumentativa del TC, son respectivamente las posiciones de R. Alonso García, El juez nacional en la encrucijada europea de los derechos fundamentales, Civitas, Madrid, 2014, en la adenda final; P. MARTín MARTínez, «Tribunal Constitucional - Sentencia 26/2014, de 13 de febrero en el recurso de amparo 6922-2008 promovido por Don Stefano Melloni», Revista de Derecho Comunitario Europeo 2014, n. ${ }^{\circ} 48$, pp. 603-622. Finalmente, en tono mucho más favorable a la posición sostenida por el Tribunal Constitucional, aun reconociendo que la sentencia «no cohonesta bien con el ATC 86/2011, de 9 de junio, (...) pues de este auto se desprendía un claro compromiso del TC con la reflexión del papel que los tribunales constitucionales debían jugar en el diseño de los contenidos de los derechos fundamentales en Europa» y aceptando que la sentencia «[t]ampoco es acorde con la solidez de la ya 'vieja' Declaración 1/2004», puede verse la contribución de C. IzQUIERdo SANS, «La callada configuración de los derechos fundamentales por el Tribunal de Justicia de la Unión Europea», en M. MíNguez Rosique/M. Pérez Manzano/J. A. Lascuraín Sánchez (dirs.), La tutela multinivel del principio de legalidad penal, Marcial Pons, Madrid 2016, pp. 57-78, especialmente pp. 74-78.

63 Cabe recordar que en una primera instancia, el Tribunal Superior de Inglaterra y Gales ( $R$ Miller $v$. Secretary of State for Exiting the EU, EWHC-2768, Case No. CO 3809/2016 y CO/3281/2016)), además de manifestar la competencia del Parlamento británico en la materia, ha entrado a interpretar el artículo 50 TUE (apdos. 15 a 17) y se ha pronunciado sobre aspectos claramente comunitarias como la irrevocabilidad e incondicionalidad de la notificación prevista en el apartado primero del mencionado artículo 50 (apdo. 10). En realidad, a tenor de lo previsto en el citado precepto del TUE, el Tribunal Supremo podría haber estado obligado a hacer uso de tal mecanismo. No ha sido, sin embargo, el caso, si bien se ha mostrado bastante más prudente en relación con esta cuestión; véase su sentencia de 24 de enero de 2017, [2017] UKSC 5, on appeals from [2016] EWHC 2768 (Adm) and [2016] NIQB 85.

64 Vid. infra, IV.2. 
balance razonablemente positivo. En realidad, mucho más que razonable en el ámbito de los derechos fundamentales, con lo que podríamos denominar $\mathrm{Paz}$ Solange; y de manera suficientemente satisfactoria, aunque aún en parte aún abierta, en el campo del posible control de los límites en la actuación de la Unión ${ }^{65}$. No en vano, resulta bastante más difícil llegar a un Paz ultra vires, ya que este control por parte del Tribunal Constitucional entronca en el fondo con la eterna discusión doctrinal, de genuino cuño germánico, sobre la Kompetenz-Kompetenz, que difícilmente será nunca reconocida a la Unión por los Tribunales Constitucionales; hacerlo equivaldría a atribuir a la Unión una de las principales señas de identidad de la Staatlichkeit.

Por ello, posiblemente, nunca un Tribunal Constitucional podrá aceptar, sin cortapisa alguna, que sea sólo el TJUE el encargado de decidir en última instancia sobre esos límites de la atribución de competencias realizadas por los Estados miembros a través de sus respectivas cláusulas constitucionales europeas. En cierto sentido, tal posicionamiento no deja de tener su sentido. Es, de hecho, la lógica que inspira el propio concepto de «identidad nacional» recogido en el artículo 4.2 TUE $^{66}$; que encarna mejor que ninguna otra disposición de los tratados constitutivos la aproximación de pluralismo jurídico al Derecho de la Unión ${ }^{67}$. Se podrá instrumentalizar a través de la vía escogida por el Tribunal Constitucional alemán; o por la (más artificiosa) distinción entre 'supremacía' (de la Constitución) y 'primacía' (del Derecho de la Unión) por la que opta el nuestro ${ }^{68}$; o por la que diseñe en su caso cada Alto Tribunal nacional, constatándose una creciente posición crítica en algunos Tribunales constitucionales (checo, polaco, danés, italiano $)^{69}$. Pero, al final, basta con temer que los Tribunales Constitucionales

65 Como bien ha explicado entre nosotros Pedro Cruz Villalón, en el fondo existen dos relatos diferentes a propósito de la interpretación del concepto básico de identidad constitucional según lo haga el TJUE o los Tribunales Constitucionales; «La identidad constitucional de los Estados miembros: dos relatos europeos», Anuario de la Facultad de Derecho de la Universidad Autónoma de Madrid 2013, vol. 17, pp. 501-514. A juicio de este autor, «cada uno de los órdenes jurisdiccionales 'está en su papel', los Tribunales Constitucionales utilizando el potencial 'esencialista' de la identidad constitucional, el TJUE proponiendo una versión 'domesticada', y acaso más operativa de la misma» (p. 514).

66 A. VON BOGDANDY y S. SCHILL, «Overcoming absolute primacy: Respect for national identity under the Lisbon Treaty», Common Market Law Review 2011, vol. 48, pp. 1417-1453; L. F. M. Besseling, «National and Constitutional Identity before and after Lisbon», Utrecht Law Review 2010, vol. 3, pp. 36-49.

67 A. von Bogdandy, loc. cit. («Overcoming...»), nota 66 especialmente pp. 1425-1426.

68 Declaración $1 / 2004$, cit., FJ. 4.

69 Ciertamente, hay algún Tribunal Constitucional al que, en nuestra opinión, se le ha podido 'ir un poco la mano' a la hora de concretar el alcance del concepto de soberanía en su interacción con las relaciones entre el Derecho de la UE y sus respectivos ordenamientos internos. Un buen ejemplo al respecto es el Tribunal checo, que en sus pronunciamientos sobre el Tratado de Lisboa (sentencia de 26 de noviembre de 2008) y, muy en especial, sobre el asunto de las pensiones eslovacas (sentencia de 3 de diciembre de 2012) ha sido particularmente crítico. También el Tribunal Constitucional polaco se pronunció en un sentido bastante restrictivo en su sentencia sobre la adhesión (sentencia de 11 de mayo de 2005). Véase, con carácter general, A. F. Tatham, Central European Constitutional Courts in the Face of EU Membership — The Influence of the German Model in Hungry and Poland, Martin Nijfoff, Leiden-Boston, 2012. En este mismo sentido, no puede pasar tampoco desapercibido que el Tribunal Supremo danés en una reciente sentencia de 6 de diciembre de 2016 
puedan ejercer in extremis ese control, para que en realidad no sea preciso verificar en la práctica su existencia. En suma, basta con proclamar, por cada uno de los dos tribunales en liza, que se sigue poseyendo la anhelada 'última palabra' en el control de los límites de la atribución competencial a la Unión, para que (de momento) no se llegue a la confrontación; o, al menos, en el caso del Tribunal Constitucional por que no ejerza dicha posibilidad sin antes consultar a quien ope legis tiene atribuida esa última potestad en el ámbito de las competencias comunitarias.

\section{LA RELACIÓN ENTRE EL TJUE Y EL TEDH: EL NUEVO RETO CONSTITUCIONAL (PENDIENTE) DEL TRIBUNAL DE JUSTICIA}

Adentrándonos ahora en el ámbito del diálogo judicial entablado entre el TJUE y el TEDH, puede constatarse que la relación entre ambos ha conocido dos fases claramente diferenciadas, separadas por la entrada en vigor del Tratado de Lisboa. Éste trajo consigo el paso de una construcción pretoriana del sistema de la Unión de protección de los derechos fundamentales (1) a un nuevo escenario en el que la conversión de la Carta de Derechos Fundamentales de la Unión en jurídicamente vinculante (art. 6.1 TUE) significó la inclusión de un catálogo obligado de derechos humanos como Derecho escrito de la Unión (2). En este contexto no puede olvidarse que ha surgido, sin embargo, un inesperado obstáculo judicial que en la práctica va a hacer muy complicada la materialización de la adhesión de la Unión al CEDH.Una adhesión que el Tratado de Lisboa previó como elemento inseparable del carácter vinculante atribuido a la Carta (3).

(asunto 14/2014) ha establecido, de manera muy preocupante, que los principios generales (no escritos) de la UE no resultan vinculantes dentro del ordenamiento jurídico danés, añadiendo severas críticas al TJUE por su supuesto activismo judicial (una versión en inglés se encuentra en http://www.supremecourt.dk/supremecourt/nyheder/pressemeddelelser/Documents/Judg ment\%2015-2014.pdf). E igualmente, el Tribunal Constitucional italiano en un pronunciamiento de 26 de enero de 2017 (ordinanza 24/2017), por el que decide plantear una cuestión prejudicial en relación con la aplicación en Italia de la previa sentencia del TJUE en el asunto Taricco (C-105/15), también vierte fuertes críticas a la jurisprudencia del TJUE en materia de;derechos humanos y viene a plantear la delicada doctrina sobre la existencia de contralímites que se plasmarían en la protección de la identidad constitucional italiana (el texto íntegro de la ordenanza se encuentra, por ejemplo, en http://www.giurisprudenzapenale.com/wp-content/uploads/2017/01/corte-cost-24-2017.pdf). En concreto, el Alto Tribunal italiano considera que los jueces nacionales no deberían aplicar las decisiones del TJUE que colísionen con principios fundamentales de la Constitución italiana (apartado 6, de la decisión de planteamiento de cuestión prejudicial). Con ello, el Alto Tribunal italiano es de la opinión de que los tribunales constitucionales han de poder retener su competencia para interpretar el alcance del concepto de identidad constitucional. En cierta forma, es un pronunciamiento que vuelve a traer a la memoria la vieja jurisprudencia italiana Fronlini de los años setenta del siglo pasado (sentencia 183/1973, de 18 de diciembre de 1973). 


\section{El diálogo judicial pre-Lisboa}

La primera de estas fases señaladas fue particularmente fértil para el diálogo judicial, ya que la ausencia de un catálogo de derechos en la Unión impulsó la imaginación y creatividad jurídica del TJUE, a la par que facilitó que la jurisprudencia del TEDH — también la de los Tribunales Constitucionales nacionalesresultase decisiva. El acercamiento del TJUE y al TEDH se fundó, por tanto, en la necesidad de colmar una laguna de los tratados constitutivos (ausencia de cualquier referencia a los derechos humanos), que en el fondo venía indirectamente impuesta por la exigencia marcada por los Tribunales Constitucionales a través de la ya aludida jurisprudencia Solage I. De esta forma, el recurso a la consideración de los derechos fundamentales como principios del Derecho Comunitario ${ }^{70}$ se fundó en primer término, como ya se ha visto, en el inteligente comodín de los derechos que resultan de las tradiciones constitucionales comunes de los Estados miembros ${ }^{71}$. Pero se basó también, en segundo término, en los tratados internacionales de protección de los derechos humanos ${ }^{72}$, básicamente el CEDH, pero también el Pacto Internacional de los Derechos Civiles y Políticos ${ }^{73}$, el Convenio 111 de la OIT $^{74}$, la Carta Social Europea ${ }^{75}$, etc.

Por su parte, en la otra orilla del diálogo, el acercamiento del TEDH al Derecho de la UE tuvo un momento inicial de cierta rivalidad, aunque menos visible que en el caso de los Tribunales Constitucionales descrito en el apartado anterior. Así, como ya hemos analizado en trabajos anteriores, del silencio inicial durante el periodo transitorio (hasta el 1 de enero de 1970) ${ }^{76}$, se entró en las décadas de los ochenta y noventa del siglo pasado en una etapa en la que daba toda la sensación de que el TEDH iba 'corrigiendo' al TJUE en la interpretación de derechos típicos del Convenio, como era el respeto al domicilio familiar ${ }^{77}$, el derecho a no

70 Stauder (26/69, ECLI: EU: C:1969:57).

71 Vid. supra, III, 1.

72 TJUE sentencia de 14 de mayo de 1974, Nold, ECLI: EU: C:1974: 51.

73 TJUE Sentencia de 18 de octubre de 1989, Orkem, ECLI: EU: C: 1989:387, apdo. 31; sentencia de 18 de octubre de 1990, Dzodzi, ECLI: EU: C: 1990:360, apdo. 68; sentencia de 17 de febrero de 1998, Franz, ECLI: EU: C: 1998:, apdos. 43 a 47.

74 TJUE sentencia de 15 de junio de 1978, Defrenne, ECLI: EU: C: 1978:130, apdo. 28.

$75 \mathrm{Ib}$.

76 En los primeros momentos de la integración europea hubo alguna decisión muy esporádica de la antigua Comisión de Derechos Humanos en la que se declaraba, sin mayor problema, falta de competencia para conocer de demandas contra la entonces Comunidad Económica Europea por no formar ésta parte del CEDH (Decisión de 10 de julio de 1978, Conféderation FranVaise Démocratique du Travail c. CEE, alternativamente contra los Estados miembros, demanda n. ${ }^{\circ}$ 8030/77).

77 Así, si el TJUE consideraba en el asunto Hoescht que el domicilio empresarial no se incluía dentro del ámbito de protección del derecho al respeto del domicilio familiar recogido en el artículo 8 CEDH (TJUE sentencia de 21 de septiembre de 1989, Hoescht c. Comisión, ECLI: EU: C: 1989: 337, apdo. 17; sentencia de 17 de octubre de 1989, Dow Benelux c. Comisión, ECLI: EU: C: 1989: 379, apdo. 28), el TEDH establecía justo lo contrario tres años más tarde en el asunto Niemietz (TEDH sentencia de 16 de diciembre de 1992, Niemietz c. Alemania, 13710/88, apdos. 29 y 31; igualmente sentencias de 16 de abril de 2002, Cosas Est y otros c. 
declarar contra sí mismo ${ }^{78}$, la libertad de expresión ${ }^{79}$ u otros ${ }^{80}$, que afloraban también en el ámbito de la Unión. Afortunadamente, esta rivalidad velada se logró superar a través de la inteligente ficción jurídica establecida por la bien conocida doctrina del TEDH sobre la 'protección equivalente', también conocida como doctrina Bosphorus ${ }^{81}$.

Con esta posición jurisprudencial el TEDH dio muestras de una 'generosidad interpretativa' frente a las peculiaridades del Derecho de la Unión, que, aunque no ha estado exenta de crítica doctrinal ${ }^{82}$, nos merece una valoración claramente positiva. Es más, tampoco han faltado casos en los que el TEDH se ha pronunciado de manera favorable para el TJUE sobre aspectos procesales de su actuación en los que se alegaba la violación del CEDH; la regla general en estos supuestos ha sido que Estrasburgo ha avalado sin fisuras la actuación judicial de Luxemburgo, ya fuere para rechazar la acusación de dilación excesiva de una

Francia, 37971/91) y posteriormente provocaba, a su vez, que el TJUE modificara su posición en el caso Roquette Frères aceptando la interpretación de aquél (TJUE sentencia de 22 de octubre de 2002, Roquette Frères, ECLI: EU: C: 2002:C: 603, apdo. 29).

78 Mientras en el asunto Orkem el TJUE no veía base en 1989 para deducir del artículo 6 del CEDH un derecho a no declarar contra sí mismo (TJUE sentencia de 18 de octubre de1989, Orkem c. Comisión, ECLI: EU:C: 1989: 387), el TEDH estipulaba justo lo opuesto en el asunto Funke resuelto cuatro años más tarde (sentencia de 25 de febrero de 1993, Funke c. Francia, 10828/84, apdo. 44).

79 Esta disparidad de interpretaciones a propósito de la libertad de expresión se planteó a propósito de si la existencia de un monopolio de televisión en un Estado era compatible con el artículo 10 CEDH. Así, mientras el TJUE consideró en el asunto ERT que la existencia de tal monopolio en un Estado miembro no violaba dicha libertad (sentencia de 10 de junio de 1991, ERT, ECLI: EU: C: 1991:254), el TEDH en el asunto Lentia establecía justo lo contrario (sentencia de 24 de noviembre de 1993, Informationsverein Lentia et al. vs. Austria).

80 Otra manifestación semejante se dio en relación con la cuestión de si la prohibición de distribuir información sobre clínicas de aborto extranjeras en un país donde se prohíbe esa práctica era contraria a esa misma libertad: mientras el Abogado General van GERVEN sostuvo en las conclusiones que presentó al asunto Grogan que tal prohibición era compatible con el artículo $10 \mathrm{CEDH}$, el TEDH decidía lo contrario un año después; véase TJUE Conclusiones del Abogado General, SPUC c. Grogan, C-159/90; TEDH sentencia de 29 de octubre de 1992, Open Door Counsellin c. Irlanda (14234/88), apdos. 72 a 74.

81 En esta fase, que se inició a mediados de la década pasada, la aparente tensión jurisprudencial reflejada en la nota anterior fue sustituida en Estrasburgo por una aceptación de la protección dada por el TJUE a los derechos fundamentales con una suerte de cláusula Solange al estilo de la empleada por el Tribunal Constitucional alemán en relación a los derechos recogidos en la Ley Fundamental de Bonn. De ahí que en asuntos como Senator Lines, el TEDH recurriese a la ficción jurídica de aceptar un recurso interpuesto por un particular contra todos los Estados que formaban parte de la misma para poder considerar a la Unión Europea como parte demandada; TEDH sentencia de 10 de marzo de 2004, Senator Lines SL c. EDM, (56672/2000). Más aún, en los conocidos asuntos Mattiews (TEDH sentencia de 10 de febrero de 1999, Matthews c. Reino Unido, cit.) o Bosphorus (TEDH sentencia de 30 de junio de 2005, Bosphorus Hava Yollari Turizm ve Ticaret Anonim Sirketi c. Irlanda, 45036/98, especialmente apdo. 153) el TEDH consideró a los Estados miembros responsables de sus actos tanto si proceden de normas internas como si lo hace de obligaciones contraídas por la pertenencia a organizaciones internacionales como la UE. En concreto, en el asunto Bosphorus el TEDH consideró que el ordenamiento jurídico de la UE ofrece en relación con los derechos humanos una protección equivalente a la del CEDH y ello permite presumir que los Estados miembros cumplen las obligaciones derivadas del Convenio cuando se limiten a aplicar obligaciones impuestas por el Derecho de la Unión.

82 Véase, por ejemplo, S. Douglas-ScotT, «A Tale of Two Courts: Luxembourg, Strasbourg and the Growing European Human Rights Acquis», Common Market Law Review 2006, n. ${ }^{\circ}$ 43, pp. 629-665. 
cuestión prejudicial $^{83}$, el inadecuado cumplimiento de una sentencia del TJUE ${ }^{84}$ o hasta recriminar a un Estado por no hacer uso de la cuestión prejudicial ante el TJUE $^{85}$. Incluso las llamadas ‘cláusulas de desconexión’ recogidas en tratados del Consejo de Europa ahondan en esta misma vía ${ }^{86}$.

Ahora bien, no puede ocultarse tampoco que el TEDH ha sabido, a la vez, sacar provecho propio de la jurisprudencia del TJUE y, así, no han sido tampoco excepción los asuntos en los que el TEDH ha llegado a emplear la jurisprudencia del TJUE como fuente complementaria para justificar su propia doctrina ${ }^{87}$. Ha sido el caso, por ejemplo, en materia de discriminación de hijos nacidos fuera del matrimonio $^{88}$, expulsiones de extranjeros con antecedentes penales ${ }^{89}$, eficacia temporal de sentencias ${ }^{90}$ o hasta la noción de 'empleo en un servicio público'.

83 Así, por ejemplo, en relación con la cuestión prejudicial en el asunto Pafitis, el Tribunal rechazó de plano la alegación de que los dos años y medio que había durado la tramitación de la cuestión prejudicial ante el TJUE pudiera suponer una violación del derecho a un proceso equitativo dentro de un plazo razonable reconocido en el artículo $6 \mathrm{CEDH}$ y respaldó plenamente la función de ese peculiar mecanismo de cooperación judicial propio del Derecho de la Unión (TEDH sentencia de 26 de febrero de 1998, Pafitis c. Grecia (20323/92), apdo. 95).

84 En el asunto Hornsby, incluso recrimina a un Estado miembro de la Unión por el hecho de que sus tribunales se negasen a aplicar exigencias derivadas de una sentencia del TJUE (TEDH sentencia de 19 de marzo de 1997, Hornsby c. Grecia,18357/91, apdo. 41).

85 Efectivamente, es posible encontrar alguna sugerencia al órgano jurisdiccional nacional para que plantease cuestión prejudicial ante el TJUE (decisiones de la Comisión de 12 de mayo de 2005, Sociedad Divagsa c. España; y de 28 de junio de 1993 Fritz y Nana S. c. Francia) o referencias a la exigencia por no cumplir adecuadamente con las exigencias del Derecho de la Unión (TEDH sentencia de 16 de abril de 2002 Dangeville c. Francia (36677/97); sentencia de 22 de julio de 2003 Cabinet Diot y SA Gras c. Francia (49217/99).

86 En efecto, desde principios de la década de los ochenta, existen en algunos convenios impulsados por el Consejo de Europa cláusulas en virtud de las cuales si uno de esos convenios entra en colisión con una norma comunitaria sobre la misma cuestión para los Estados miembros de la UE prevalece la norma comunitaria. Se hizo por primera vez, que sepamos, en el Convenio de sobre Televisión Transfronteriza de 5 de mayo de 1989. Otro ejemplo lo brinda el artículo 26.3 del Convenio Europeo sobre Prevención del Terrorismo de 16 de mayo de 2005 .

87 R. LAwsON, «Ex Boreale Lux: On the Influence of the ECJ on the Interpretation of the ECHR», en Liber amicorum Piet Jan Slot, 2009, p. 439.

88 En una sentencia tan temprana como la dictada en 1979 en el asunto Marckx cuando, al tener que resolver si las discriminaciones sufridas en Bélgica por hijos nacidos fuera del matrimonio eran contrarias al CEDH, se amparó en la jurisprudencia Defrenne del TJUE; TEDH sentencia de 13 de junio de 1979 Marckx c. Bélgica (6833/74), apdo. 58.

89 Así, por ejemplo en el caso Maslov, en el que se analizaba si la expulsión realizada por Austria de un joven búlgaro con antecedentes penales era compatible con el Convenio, el TEDH al dictar su sentencia tuvo en cuenta tanto la Directiva comunitaria sobre la materia (Directiva 2004/38/CE del Parlamento Europeo y del Consejo, de 29 de abril de 2004, relativa a los derechos de los ciudadanos de la Unión y de los miembros de sus familias a circular y residir libremente en el territorio de los Estados miembros, DO L 158 de 30.4.2004, p. 77, especialmente su artículo 28.3) como lo resuelto por el TJUE en los asuntos Orfanopoulos (TJUE sentencia de 29 de abril de 2004, Orfanopoulos y Oliveri, ECLI: EU: C: 2004: 262) como el asunto Comisión c. España (TJUE sentencia de 31 de enero de 2006, Comisión c. España, ECLI: EU: C: 2006: 74); TEDH sentencia 23 de junio de 2008, Maslov c. Austria (1638/03), apdos. 82 y 93.

90 El TEDH se ha separado en alguna ocasión de lo que tradicionalmente ha sido tónica habitual en el entorno judicial europeo, esto es, que las sentencias de los órganos jurisdiccionales tienen una eficacia entre las partes desde el mismo momento en que se dicta la referida sentencia. De la misma forma que el TJUE en el segundo asunto Defrenne no aceptó que del efecto directo de la prohibición de discriminación por razón del 
Bien puede hablarse, pues, de un diálogo judicial bidireccional con un aprovechamiento mutuo de las respectivas jurisprudencias.

Ello, por supuesto, no es óbice para constatar que, como en todo diálogo judicial, han existido también algunas disfunciones de cierta entidad. Estas, en el fondo, han girado en torno a cuál de las dos instancias, Luxemburgo o Estrasburgo, habrían de disponer de la 'última palabra', lo que en contadas ocasiones ha conducido a soluciones divergentes ante los mismos hechos ${ }^{91}$ o a que el TEDH trate de preservar alguna cautelas para sustentar una cierta preeminencia de su jurisprudencia cuando se trate de derechos recogidos en el CEDH. En realidad, ni siquiera la adhesión de la Unión al CEDH podría eliminar por completo la posibilidad de divergencias ${ }^{92}$.

\section{El diálogo judicial post-Lisboa}

Sin embargo, la entrada en vigor de las novedades que introducía el Tratado de Lisboa acarreaba la creación de un nuevo marco jurídico para la protección

sexo en el salario (entonces art. 119 TCEE, en la actualidad art. 157.1 TFUE) pudiera tener un efecto retroactivo entre las partes con fundamento en consideracones de seguridad jurídica (TJUE Sentencia de 8 de marzo de 1976, Defrenne c. Sabena, ECLI: EU: C: 1976: 56), el TEDH llegó a una conclusión muy semejante en el asunto Marckx (TEDH, sentencia de 27 de abril de 1979, Marckx c. Bélgica). De esta manera, tres años después de la sentencia Defrenne, el TEDH dictaminó con toda rotundidad que la normativa belga que establecía una diferencia entre hijos legítimos e ilegítimos en relación con la filiación y los derechos de los hijos en el acceso a la propiedad de los bienes de la madre violaba el derecho a la vida familiar recogido en el artículo $8 \mathrm{CEDH}$. Consideró, empero, que los efectos de la sentencia se limitarían a los hechos que se produjeran en el futuro y la controvertida fundamentación de la sentencia se hizo también en razón del principio de seguridad jurídica (ib. apdos. 14 y 15$)$

91 En efecto, resulta perfectamente posible encontrar sentencias en las que, ante hechos muy semejantes, ambos tribunales lleguen a conclusiones radicalmente contrarias. La dispar solución jurídica en los asuntos Kadi (TJUE sentencia de 3 de septiembre de 2008, Kadi, ECLI: EU: C: 2008:461) y Bebrami (TEDH sentencia de 31 de mayo de 2007 Bebrami c. Francia y Noruega $(71412 / 01)$ es un buen ejemplo de ello. Se pueden encontrar también algún caso en el que, como ocurría en los asunto Vajnai (TEDH sentencia de 8 de julio de 2008, Vajnai c. Hungría (33629/06); TJUE auto de 6 de octubre de 2005, Vajnai (ECLI: EU: C: 2005: 684), apdo. 14) y Koua Poirrez (TEDH sentencia de 30 de septiembre de 2003, Koua Poirrez c. Francia (40892/98), apdo. 46; TJUE sentencia de 16 de diciembre de1992, Koua Poirrez (ECLI: EU: C: 1992: 523) se constate en Estrasburgo una protección más intensa que la dada por Luxemburgo. O al revés, sentencias en las que, como era el caso de los asuntos Rees y Cossey, el TEDH mantenía un nivel de protección inferior al del TJUE ya que aquél no consideraba exigible que el Reino Unido reconociera los derechos de los transexuales (TEDH sentencia de 17 de octubre de 1986 Rees c. Reino Unido (9532/81); sentencia de 27 de septiembre de 1990, Cossey c. Reino Unido (10843/84)), mientras que en el ámbito de la Unión en el asunto $P$ c. $S$ ya se les había reconocido una equiparación de derechos (TJUE sentencia de 30 de abril de1996, $P$ c. $S$ y Cornwal County Council, ECLI: EU: C: 1996: 170); quizá por eso precisamente el TEDH modificó posteriormente su posición en el ya citado asunto Goodwin.

92 A la postre, incluso tras la adhesión de la UE al CEDH, pervivirán este tipo de divergencias porque derivan de la propia especificidad del ordenamiento jurídico de la UE. El TEDH se desenvuelve en el marco de un acuerdo internacional de carácter intergubernamental en el que los mecanismos judiciales en su mano son los propios de un sistema de (mera) cooperación internacional, mientras que el TJUE actúa en el marco de un ordenamiento jurídico supranacional con resortes judiciales muy semejantes a los existentes en sus Estados miembros. 
multinivel de los derechos fundamentales en el espacio jurídico europeo basado en el Derecho escrito y la mayor certeza jurídica ${ }^{93}$, derivada del carácter vinculante de la Carta (art. 6.1 TUE) ${ }^{94}$. Esta relevante novedad, unida a la ya citada atribución competencial del artículo 6.2 TUE para la adhesión de la Unión al $\mathrm{CEDH}$, conllevaba al menos cinco consecuencias adicionales.

En primer lugar, el Tratado de Lisboa no encarnaba ruptura alguna respecto a la situación anterior, ya que se garantizaba una continuidad de la jurisprudencia del TJUE a través del cabal mantenimiento de los derechos del CEDH como principios generales del Derecho de la Unión (art. 6.3 TUE) ${ }^{95}$. Obviamente, la existencia de la Carta con carácter jurídicamente vinculante exigirá una lógica modulación jurisprudencial que indefectiblemente deberá centrar su protagonismo en la Carta ${ }^{96}$. Pero este mantenimiento flexible de los derechos como principios generales del Derecho de la Unión cobraba particular relevancia en relación con aquellos derechos que en la Carta tienen un alcance más limitado - sólo frente a actos de las institucionales de la Unión (art. 41 Carta) ${ }^{97}$ - y que en la doctrina jurisprudencial previa también engloba a los Estados cuando aplican

93 En todo caso, resulta, cuanto menos curiosa, la caracterización que el Presidente del TJUE ha hecho de la Carta de Derechos Fundamentales de la Unión. Describe la Carta «como una sombra del Derecho de la Unión; de manera que de la misma forma que un objeto forma los contornos de su sombra, también el Derecho de la Unión determina los contornos de la Carta»; K. LENAERTs, «In Vielfalt geeint — Grundrechte als Basis des europäischen Integrationsprozesses», Europäsiche Grundrechte Zeitschrift 2015, pp. 353-361, en p. 354 («...handelt es sich bei der Charta um den Schatten des Unionsrechts. So wie ein Gegenstand die Konturen seines Schattens formt, bestimmt auch das Unionsrecht die 'Konturen' der Charta).

94 Sobre la Carta de Derechos Fundamentales de la Unión Europea puede verse, por todos, A. MANGAS MARTín (coord.), La Carta de Derechos Fundamentales de la Unión Europea - Comentario artículo por artículo, Fundación BBVA, Madrid, 2008. A propósito de la relación entre la Carta y los catálogos internos de derechos humanos puede verse, entre los muchos trabajos existentes, R. Alonso GARcía, op. cit. (El juez nacional...), nota 62, especialmente su capítulo II. A este respecto, sigue siendo cuestión central el análisis de la jurisprudencia Melloni y Akerberg del TJUE en relación con el artículo 53 de la Carta, en particular las incertidumbres y ambigüedades que genera la consideración Melloni de que el estándar de protección suministrado por la Carta desplaza a los estándares nacionales de protección, incluso aunque estos sean superiores, siempre y cuando el Derecho de la Unión no atribuya a los Estados margen de apreciación en relación con la aplicación de aquél.

95 TJUE sentencia de 19 de enero 2010, Kücükdeveci, ECLI: EU: C: 2010: 21; sentencia de 14 de septiembre de 2010, Akzo Nobel Chemicals c. Comisión, ECLI: EU: C: 2010: 512.

96 Resulta evidente que, con carácter general, la entrada en vigor del Tratado de Lisboa y la consiguiente incorporación por referencia de la Carta a los tratados constitutivos ha traído como primera consecuencia una cierta pérdida de protagonismo (al menos cuantitativo) de la jurisprudencia del TEDH. Ya no resulta necesario que cada sentencia del TJUE en materia de derechos humanos intente buscar su respaldo último en la doctrina del TEDH, ya que este papel protagonista del CEDH como principios generales del Derecho de la UE, ha sido sustituido por la Carta. De hecho, no son ya excepción las sentencias en las que resulta llamativa la ausencia de referencias a la jurisprudencia del TEDH. Quizá el relevante asunto Akerberg pueda ser buen botón de muestra que no ha pasado desapercibido a la doctrina; C-617/10, ECLI: EU: C:2013: 280. Ahora bien, resulta previsible la utilidad potencial de la jurisprudencia del TEDH en los contados casos en los que el estándar de protección del CEDH resulte superior al suministrado por la Carta.

97 Recuérdese que en el conocido asunto Mangold (C-144/04) el TJUE utilizó la Carta como elemento fundamental para constatar el derecho de no discriminación por razón de la edad como un principio general de Derecho existente en la UE; ECLI: EU: C: 2005: 709. 
Derecho de la Unión. El derecho a ser oído en un procedimiento administrativo podría ser un buen ejemplo ${ }^{98}$.

En segundo lugar, el carácter jurídicamente vinculante de la Carta demandaba igualmente una respuesta satisfactoria a cuestiones complejas como el estándar de protección y las relaciones (materiales) en cada caso concreto entre los tres órdenes jurídicos en juego, los cuales disponen de un catálogo propio de derechos humanos (Constituciones nacionales, Carta y CEDH). Por lo que respecta al estándar de protección, el artículo 52.3 de la Carta deja claro que en el supuesto — mayoritario en la práctica — de derechos recogidos en el CEDH «su sentido y alcance serán iguales a los que le confiere dicho Convenio» ${ }^{99}$. Sin embargo, la práctica ha demostrado la dificultad de su concreción y la facilidad de potenciales conflictos entre el TJUE y el TEDH. Así, tenemos un buen botón de muestra bien reciente en el ámbito del problemático principio ne bis in idem, más especialmente en relación con la posibilidad de acumulación de sanciones penales y administrativas de naturaleza penal en el ámbito fiscal. Mientras el TJUE modificó su jurisprudencia anterior y en el asunto Hans Akeberg Fransson, siguiendo la doctrina más estricta fijada antes por el $\mathrm{TEDH}^{100}$, se manifestó en sentido contrario a la acumulación ${ }^{101}$, el TEDH acaba de reconsiderar su posición anterior y en el asunto $A$ y $B$ c. Noruega la Gran Sala se ha pronunciado en sentido favorable a la acumulación bajo el criterio del «lien matériel et temporel suffisamment étroit» ${ }^{102}$.

Queda ahora, pues, el TJUE en la tesitura de decidir en un caso pendiente ante la Gran Sala si se decanta por hacer uso del artículo 52 de la Carta para propugnar en el ámbito de la UE un estándar de protección más alto — que coincidiría con el fijado anteriormente por el TEDH y conforme al cual algunos Estados de la UE ya habían modificado sus legislaciones internas — o, si por el contrario, decide asumir sin más la nueva doctrina del $\mathrm{TEDH}^{103}$. Si se decantara por la primera opción, bien

98 Cfr. D. Sarmiento, El Derecho de la Unión Europea, Marcial Pons, Madrid, 2016, pp. 176-177 y nota 52 .

99 Cfr. A. Mangas Martín, «Art. 52», en ib. (coord.), op. cit. (La Carta...), nota 94, pp. 826-851.

100 Cabe citar en materia fiscal la sentencia del TEDH de 27 de noviembre de 2014, Lucky Dev c. Suecia , nd. ${ }^{\circ}$ 7356/10, apdo. 58; en materia bursátil, sentencia de 4 de marzo de 2014, Grande Stevens y otros c. Italia, n. $^{\circ}$ 18640/10, 18647/10, 18663/10 y 18698/10; finalmente en el ámbito aduanero, sentencia de 30 de abril de 2015, Kapetanios y otros c. Grecia, n. ${ }^{\circ} 3453 / 12,42941 / 12$ y 9028/13.

101 TJUE sentencia de 26 de febrero de 2013, C-617/10, cit.

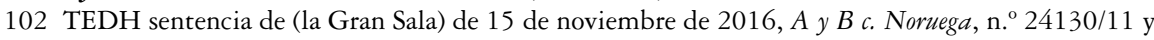
29758/11, especialmente apartados 124 y 125. La sentencia tiene un voto particular muy crítico del juez Pinto de Alburquerque, quien considera que la interpretación dada por la Gran Sala al derecho de ne bis in idem lo convierte en «un droit aussi fluide, étroiement interprété, en un mot: illusoire» (apdo. 80 in fine).

103 Se trata del asunto C-524/15 Luca Menci, en el que se analiza la compatibilidad con la Carta de la ampliación de sanciones por delitos iniciados en mercados financieros. Es una cuestión prejudicial planteada por el Tribunale di Bergamo en el que se plantea al TJUE la pregunta de si se opone al artículo 50 de la Carta, interpretado a la luz del artículo 4 del Protocolo 7 del CEDH y de la jurisprudencia el TEDH, la posibilidad de tramitar un proceso penal que tenga por objeto un hecho (impago del IVA) por el cual se haya impuesto a la persona imputada una sanción administrativa irrevocable; DOUE C 414, de 14 de diciembre de 2015, p. 22. 
podría darse, en este sentido, una suerte de 'Melloni a la inversa' ex artículo 52 de la Carta. No obstante, una decisión divergente de la adoptada por el TEDH podría afectar también a la colaboración entre ambos tribunales ${ }^{104}$. El problema principal es que casos similares pueden surgir en relación con otros derechos del CEDH.

En tercer lugar, en relación con los elementos procedimentales derivados de la existencia de tres niveles judiciales en juego, a la postre, no puede obviarse lo que AlOnso García ha denominado 'la encrucijada procedimental o formal' en la que puede encontrarse el juez nacional en un supuesto de adhesión de la UE al $\mathrm{CEDH}$, ya que podrían concurrir casos en los que cupiese la opción entre la cuestión prejudicial al TJUE, la consulta al TEDH con base en el Protocolo 16 o, en los casos en los que como ocurre en España exista, la cuestión de inconstitucionalidad ante el Tribunal Constitucional ${ }^{105}$. A este respecto, por cierto, una interesante cuestión pendiente de mayor y mejor escrutinio por nuestro Tribunal Constitucional es la relativa a la posible vulneración del principio constitucional de tutela judicial efectiva (art. 24 de la Constitución) por un órgano jurisdiccional nacional como consecuencia del no uso del mecanismo de la cuestión prejudicial, que es tanto como considerar si el Tribunal Constitucional ha de asumir un papel de garante (nacional) del adecuado uso del artículo 267 TFUE ${ }^{106}$.

En cuarto lugar, fruto de ello, resultaba más necesaria que nunca una intensificación del diálogo judicial entre el TJUE y el TEDH con miras a superar de manera leal las dificultades derivadas de las peculiaridades de la Unión en

104 En su voto disidente, el juez Alburquerque consideró que «[l]a collaboration progressive et mutuelle entre les deux cours européennes va de toute évidence être encore une fois prfondément perturbée, Strasbourg allant dans la mauvaise direction quand Luxembourg prend la bonne»; cit., apdo. 80.

105 R. Alonso García, op. cit. (El juez nacional...), nota 62, p. 16 y desarrollado en pp. 85-109. A este respecto, a la luz de la jurisprudencia del TJUE, ni cabe sostener la prevalencia del control incidental de constitucionalidad sobre la cuestión prejudicial (jurisprudencia Melki y Abdeli, C-188/10 y C-189/10, ECLI: EU:C:2010:363) ni cabe subordinar la inaplicación de una norma nacional al previo planteamiento de una cuestión prejudicial (jurisprudencia Kükükedeveci) y, obviamente, en caso de concurrencia de una cuestión prejudicial y una cuestión de inconstitucionalidad el Tribunal Constitucional no podrá resolver esta última sin antes esperar al pronunciamiento del TJUE (jurisprudencia Jeremy). Véase in extenso sobre esta cuestión, P. CruZ VILLALón y J. L. Requejo PAGÉs, «La relación entre la cuestión prejudicial y la cuestión de inconstitucionalidad», Revista de Derecho Comunitario Europeo 2015, n. ${ }^{\circ}$ 50, pp. 173-194, especialmente su propuesta de que el juez, en la medida de lo posible, siga el criterio de la 'simultaneidad' en lugar del de 'sucesión temporal'.

106 En la STC 212/2014, de 18 de diciembre, el TC parece asumir la doctrina de que, como indica el voto particular de la magistrada Adela Asúa, «la infracción del artículo 267 TFUE no afecta al artículo 24 CE salvo en el supuesto de que el Juez ordinario haya realizado una aplicación arbitraria, manifiestamente irrazonable o fruto de un error patente». En cierto modo, podría parecer que el TC decide no seguir el camino más pro-comunitario que parecía haber abierto en la STC 58/2004 y mantener el criterio sostenido, por ejemplo, en la STC 27/2013, de 11 de febrero. Ello, a nuestro entender, conduce a una muy discutible interpretación de la doctrina del acto claro. En un sentido más favorable a la posición del TC puede verse la contribución de C. IzQUIERDo SANS, «Amparo constitucional y cuestión prejudicial ¿un nuevo giro del Tribunal Constitucional? Comentario a la STC 212/2014, de 18 de diciembre», Revista Española de Derecho Europeo 2016, n. ${ }^{\circ}$ 55, pp. 107-132, especialmente pp. 129-132. Por lo que se refiere a la posición del TJUE, la jurisprudencia Melki deja claros los límites al posible uso (preferente) de la cuestión de inconstitucionalidad, salvo que se trate de casos de una transposición de disposiciones imperativas de una directiva; ECLI: EU: C: 2010: 363). 
relación con los Estados Parte del $\mathrm{CEDH}$, en especial en relación con el principio de autonomía del Derecho de la Unión y el monopolio del TJUE en el control de validez de los actos de la Unión. Mas se supone que esta situación era transitoria y se vería superada una vez se materializara el pleno control judicial externo del TEDH respecto a posibles violaciones de derechos contenidos en el CEDH por la Unión o por sus Estados miembros en aplicación de Derecho de la Unión. Para ello la generosa ficción asumida por el TEDH en la ya citada doctrina Bosphorus ${ }^{107}$, mantenida sin cambios tras la aprobación de la Carta ${ }^{108}$ y también tras la entrada en vigor del Tratado de Lisboa ${ }^{109}$, era buen freno de contención provisional a la espera de cerrar el sistema con la definitiva adhesión de la Unión al CEDH.

Precisamente por ello, en quinto lugar, cobraba capital importancia esta última pieza del puzzle, a saber, la adhesión de la Unión al CEDH que, tras no pocas cuitas previas (doctrinales, jurisprudenciales y políticas), los Estados miembros decidieron en Lisboa insertarla en el artículo 6.2 TUE. Sin embargo, a la hora de materializar este último paso, el TJUE ha dinamitado tal vía. Al enfrentarse a uno de sus más relevantes retos constitucionales de su existencia, lejos de mostrar la esperable altura de miras, ha dado muestra de una miopía institucional difícilmente comprensible desde

107 Un análisis de la jurisprudencia posterior a 2005 (hasta 2014) en aplicación del principio de protección equivalente se puede encontrar en R. Alonso GARCía, op. cit. (El juez nacional...), nota 62, especialmente el capítulo III. Particular relevancia (y atención de este autor) cobra el interesante asunto Michaud c. Francia de 2012 en el que en un supuesto de inadecuada transposición francesa de la Directiva sobre blanqueo de capitales podemos encontrarnos con una norma nacional que puede resultar contraria tanto a la Directiva como al CEDH y en la que, en ausencia de planteamiento (debido) de cuestión prejudicial por el Consejo de Estado francés, no cabe aplicar la doctrina de la protección equivalente como consecuencia del amplio margen de apreciación dejado por la Directiva a los Estados miembros de la Unión para su transposición.

108 En efecto, la posición jurisprudencial mantenida por el TEDH en los términos expresados anteriormente (vid. supra), ha continuado una vez aprobada la Carta de Derechos Fundamentales de la Unión. El TEDH ha recurrido a ella en abundantes ocasiones, incluso antes de que con la entrada en vigor del Tratado de Lisboa adquiriese ésta carácter jurídicamente vinculante. Quizá el caso más representativo lo constituya el conocido asunto Goodwin; TEDH sentencia de 11 de julio de 2002, Goodwin c. Reino Unido (28957/95). El TEDH, tuvo que decidir si el Reino Unido había violado diversos derechos del CEDH al negarse a facilitar a una mujer transexual un número de afiliación a la seguridad social para evitar discriminaciones en el trabajo y permitirle además acceder a una jubilación como mujer (a los 60 años) en lugar de como hombre (a los 65 años) y para hacerlo el Tribunal recurrió tanto a la Carta de la UE (art. 9) como a la jurisprudencia del TJUE en materia de discriminación sexual a los transexuales. En concreto, la sentencia del TEDH cita la sentencia del TJUE de 30 de abril de 1996, P c. S y Cornwall County Council, ECLI: EU: C: 1996: 170). En ella el TJUE consideró que la discriminación de los transexuales constituía una discriminación sexual prohibida por el artículo 5.1 de la Directiva 76/207/CEE del Consejo, de 9 de febrero de 1976, relativa a la aplicación del principio de prohibición de igualdad de trato entre hombres y mujeres en lo que se refiere al acceso al empleo, a la formación y a la promoción profesionales, y a las condiciones de trabajo. El Reino Unido, por su parte, se apoyó también en el precepto de la Directiva 79/7/CEE, relativa a la aplicación progresiva del principio de igualdad de trato entre hombres y mujeres en materia de seguridad social, que autorizaba su aplicación progresiva (art. 7.1), así como también en lo establecido por el TJUE en su sentencia de 7 de julio 1992, The Queen c. Secretary of State for Social Security, ECLI: EU: C: 1992: 54). Sobre esta base, el citado Tribunal constató finalmente una violación tanto del derecho a la vida privada y familiar (art. $8 \mathrm{CEDH}$ ) como del derecho de matrimonio (art. 12 CEDH).

$109 \mathrm{Al}$ margen de otros ejemplos de cierta relevancia en la jurisprudencia más reciente del TEDH, merece la pena llamar la atención sobre la importante sentencia de la Gran Cámara recaída el 12 de septiembre 2012 en el asunto Nada c. Suiza (Asunto 10593/08). 
paradigmas estrictamente jurídicos. Ciertamente, como acabamos de mostrar, la adhesión no hubiera resuelto todos los problemas que en materia de derechos humanos se plantean en el espacio jurídico europeo como consecuencia de la convergencia de tres ordenamientos diferentes con catálogo de derechos y mecanismos judiciales propios para su protección. Pero, una vez incluida en los tratados constitutivos la previsión competencial del artículo 6.2 TUE en los términos en que se hizo en Lisboa, lo menos que se esperaba del TJUE era una interpretación que tuviera en cuenta el 'efecto útil' de la previsión del TUE en el mismo sentido que el Alto Tribunal de la Unión impone a los tribunales nacionales. Pero no fue así.

\section{El portazo del TJUE a la adhesión de la Unión al CEDH}

Antes al contrario. En su pronunciamiento de 18 de diciembre de 2014 sobre la adhesión de la Unión al CEDH, el TJUE consideró que el Proyecto de Acuerdo de Adhesión de la UE, negociado básicamente entre el grupo de trabajo informal y la Comisión ${ }^{110}$, no era compatible con el artículo 6.2 TUE ni con el Protocolo n. 8 TUE $^{111}$. Tal incompatibilidad derivaba de cinco elementos fundamentales, a saber, las características específicas y el principio de autonomía del Derecho de la Unión ${ }^{112}$, el alcance del artículo 344 TFUE $^{113}$, la figura del codemandado $^{114}$, el mecanismo de intervención previa del TJUE ${ }^{115}$ y el control jurisdiccional de la Política Exterior y de Seguridad Común (PESC) ${ }^{116}$. De esta manera, el TJUE, a diferencia de lo propuesta de manera bastante más constructiva que elaboró en sus conclusiones la Abogada General KOKOTT ${ }^{117}$, optó por una interpretación tan extensiva del principio de autonomía del Derecho de la Unión que, francamente, ha desvirtuado por completo el mandato del artículo 6.2 TUE hasta convertir la adhesión en misión 'casi' imposible.

No parece necesario reiterar las duras críticas que a nuestro juicio merece el dictamen $2 / 13^{118}$ ni las consecuencias paralizantes que tiene para el proceso de

110 El cuerpo jurídico objeto de examen lo constituyen cinco instrumentos diferentes consistentes en un Proyecto de Acuerdo relativo a la Adhesión de la UE al CEDH, un proyecto de declaración de la UE en el momento de la firma del acuerdo, un proyecto de norma para añadir a la Normas del Comité de Ministros para la supervisión de la ejecución de las sentencias, un Proyecto de entendimiento entre la UE y X y un Proyecto de informe explicativo. Los documentos pueden consultarse, por ejemplo, en CDDH-UE (2011) 16 de 19 de julio de 2011 o en CDDH (2011) 009 de 14 de octubre de 2011.

111 Dictamen 2/2013, de 18 de diciembre de 2014, cit.

112 Apartados 179 a 200.

113 Apartados 201 a 214.

114 Apartados 215 a 235.

115 Apartados 236 a 248.

116 Apartados 249 a 258.

117 ECLI:EU:C:2014:2475.

118 Ya las hemos expresado con anterioridad de manera bastante contundente en nuestro trabajo «El TJUE pierde el rumbo en el dictamen 2/13: ¿Merece todavía la pena la adhesión de la UE al CEDH?», Revista 
adhesión de la UE al CEDH ${ }^{119}$. Sí puede resultar útil, empero, recordar en relación con el tema tratado en este trabajo cuatro cuestiones principales. En primer lugar, cuantas más veces se (re)lee la argumentación jurídica del dictamen, más sonoro se hace el silencio absoluto a propósito del valor constitucional del mandato de adhesión de la UE al CEDH recogido en el artículo 6.2 TUE. El Alto Tribunal parece hacer 'como si' dicho precepto no figurase en los tratados constitutivos; como si los Estados no hubieran decidido conscientemente incluir una formulación tan rotunda como la escogida por el Tratado de Lisboa ${ }^{120}$. Difícilmente puede disiparse, por tanto, la sospecha de que, en su íntima convicción, el TJUE consideró inadecuada la inclusión de este precepto en los tratados constitutivos, como de hecho dejaron traslucir a las claras algunas de las preguntas formuladas por los jueces en la vista oral del 5 y 6 de mayo de 2013. Y, salvo que se opte por adentrarse en la delicada (y nada recomendable) cuestión de si una disposición incluida en los tratados constitutivos puede ser contraria a los mismos ${ }^{121}$, parece muy discutible que tal tarea no corresponda al TJUE sino, más bien, a los Estados miembros.

de Derecho Comunitario Europeo 2015, n. ${ }^{\circ} 52$, pp. 825-869. A nuestro entender, 'autonomía no es lo mismo que autismo' (pp. 833-844), 'diálogo no es lo mismo que monólogo' (pp. 844-849) y dificultad (técnica) no lo es lo mismo que imposibilidad (total)', sino más bien una falta de voluntad interpretativa conforme al artículo 6.2 TUE (pp. 849-856) que indefectiblemente nos conduce a la cuestión de si 'sigue mereciendo la pena la adhesión de la UE al CEDH' (pp. 856-869).

Desde luego, estamos muy lejos de encontrarnos sólo en esta crítica. Sin ánimo exhaustivo alguno, pueden verse las duras valoraciones de, por ejemplo, C. Tomuschat, «Der Streit um die Auslegungshoheit: die Autonomie der EU als Heiliger Gral — Das EuGH-Gutachten gegen den Beitritt der EU zur EMRK», Europäische Grundrechte-Zeitschrift 2015, vol. 42, pp. 133-139; P. GRAGL, «The Reasonableness of Jealousy: Opinion 2/13 and EU-Accession to the ECHR», European Yearkbook of Human Rights 2015, pp. 27-49; J. P. JACQUÉ, «CJUE-TEDH: 2-0», Revue Trimestrielle de Droit Européen 2014, pp. 823-831.

119 Lo mínimo que puede decirse al respecto es que el proceso se retrasará durante mucho tiempo y requerirá no pocos malabarismos negociadores. Véase M. AzPITARTE SÁNCHEZ, «Los derechos fundamentales de la Unión en busca de un nuevo equilibrio», Revista Española de Derecho Constitucional 2015, n. ${ }^{\circ} 104$, pp. 243-268; T. Lock: «The future of the European Union's accession to the European Convention on Human Rights after Opinion 2/13: is still possible and is still desirable», European Constitutional Law Review 2015, vol. 11, pp. 239-279.

120 Recuérdese que este precepto establece de manera taxativa que «la Unión se adherirá al Convenio» (cursiva añadida por nosotros). No dice que «podrá adherirse» o «favorecerá la adhesión» o que «contribuirá a la adhesión», como es el caso en otros preceptos de los tratados constitutivos.

121 Esta discusión es bien conocida en el ámbito constitucional, especialmente en el germánico; véase, por ejemplo, O. Pfersmann, «Unconstitutional constitutional amendments: a normativist approach», Zeitschriftt für öffentliches Recht 2012, n. ${ }^{\circ}$ 67, pp. 81-113 (traducido al español por Carlos Ruiz Miguel y publicado en «Reformas constitucionales inconstitucionales: una perspectiva normativista», Revista Española de Derecho Constitucional 2013, n. ${ }^{\circ}$ 99, pp. 17-69). Se trata, de cualquier manera, de una discusión más doctrinal que jurisprudencial, ya que si bien no son excepción los tribunales que han barajado esta hipótesis (el Tribunal Constitucional alemán lo ha hecho en varias ocasiones; BVerfGE 1, 14; BVerfGE 3, 225, etc.), no es fácil encontrar ejemplos reales de decisiones en las que se haya anulado o declarado inconstitucional un precepto incluido en una Constitución formal. Ciertamente pueden tenerse en cuenta los casos austríaco (Decisión de 11 de octubre de 2011, VfSlg 16.327/2001) o checo (Decisión de 10 de septiembre de 2009), pero son supuestos tan específicos (concesiones públicas y acortamiento del mandado de una legislatura respectivamente) y particulares (ubicados indirectamente en leyes de reforma constitucional) que difícilmente pueden ser elevados a categoría. Otra cosa es que, como ya se ha indicado ut supra, a partir de la cláusula de 
En segundo lugar, en conexión con esta misma cuestión, la realidad es que la posición sostenida por el Tribunal de Justicia supone en la práctica una directa colisión de pareceres entre él y todos los demás actores en liza. En primer término, frente a las instituciones de la Unión (Comisión, Consejo y Parlamento Europeo), que sostuvieron claramente ante el Tribunal un respaldo a la adhesión en los términos fijados en el Acuerdo negociado. En segundo término, frente a los Estados, que, desde perspectivas dispares, hicieron gala de interpretaciones jurídicas imaginativas tendentes a buscar líneas argumentales para poder defender en último extremo la compatibilidad del Acuerdo de adhesión con los tratados constitutivos.

En tercer lugar, el pronunciamiento del TJUE también entra en colisión con el propio TEDH, que ofrecía el criterio de la 'protección equivalente' como fórmula transitoria hasta la definitiva adhesión de la Unión al CEDH y, con ello, la aceptación del control judicial externo de la Unión en materia de derechos humanos por parte del Tribunal de Estrasburgo.

En cuarto lugar, bien podría pensarse incluso que el TJUE entra en colisión consigo mismo, ya que, sin que nadie lo instara y muchos no lo comprendieran, su presidente suscribió junto al presidente del TEDH una declaración de la que todos los operadores dedujeron que marcaba la pauta para que Acuerdo de adhesión pudiera salvar el 'listón de constitucionalidad comunitaria' a establecer por el TJUE ${ }^{122}$. Ciertamente, nadie duda que sea competencia del TJUE controlar la compatibilidad del Acuerdo negociado con los tratados constitutivos en los términos previstos en el artículo 218.11 TFUE; y es tarea propia señalar, por tanto, los posibles elementos del Acuerdo que, a su juicio, no resultan compatibles con los tratados constitutivos. Pero no encaja tanto en esa función la ya aludida crítica subliminal a la forma de negociar el acuerdo ${ }^{123}$ o, menos aún, la sutil crítica a los

intangibilidad del artículo 79.3 de la Ley Fundamental de Bonn el Tribunal Constitucional alemán haya considerado oportuno considerar que de dicha cláusula no ha de derivarse forzosamente una interpretación absoluta sin posibilidad de límites, siendo competencia suya su establecimiento concreto (BVerfGE 30, 1), si bien, hasta donde conocemos, nunca hasta el momento los ha precisado. Por lo que respecta a nuestra propia Constitución esta misma cuestión se plantea en relación, por ejemplo, con la preferencia masculina en la sucesión de la Corona (art. 57.1 CE).

122 Efectivamente, el 17 de enero de 2011 tuvo lugar una curiosa reunión entre delegaciones del TJUE y del TEDH en la que, entre otras cuestiones, se abordó la cuestión de la eventual implicación del TJUE en aquellos asuntos en los que la UE actuase como codefensor y concluyó con una Declaración conjunta de los presidentes de ambos tribunales. Con anterioridad el TJUE, sin que nadie se lo hubiera sugerido, había publicado su posición ante esta cuestión; Documento de reflexión del Tribunal de Justicia de la Unión Europea sobre determinados aspectos de la adbesión de la Unión Europea al Convenio Europeo para la Protección de los Derechos Humanos y de las Libertades Fundamentales, Luxemburgo, 5 de mayo de 2010.

123 Aunque hecho en el marco de la doctrina y no en el jurisprudencial, un miembro del TJUE ha considerado que «l'accord d'adhésion constitue une oeuvre pleine de improvisation (...) qui (...) risque d'avoir des conséquences imprévisibles»; J. MALEOvsky, «Comment tirer parti de l'avis 2/13 de la Cour de l'Union européennne sur l'adhésion à la Convention européenne des droits de l'Homme», Revue Général de Droit International Public 2015, vol. 119, pp. 705-742, en p. 739. 
propios Estados miembros por haber incluido en los tratados constitutivos una disposición como la recogida en el artículo 6.2 $\mathrm{TUE}^{124}$.

En todo caso, mirando hacia el futuro inmediato conviene constatar que, desde la perspectiva estrictamente jurídica, que es la que aquí nos interesa, no faltan posibles vías de salida a la situación generada por el dictamen 2/13 del Tribunal de Justicia. En este sentido, sin que sea posible entrar en mayores detalles en esa sede, el director de la asesoría jurídica del Consejo de Europa para temas de Derecho Internacional ha publicado recientemente un interesante trabajo en el que intenta vislumbrar estas vías jurídicas para superar los obstáculos a la adhesión planteados por el TJUE en su dictamen ${ }^{125}$. No será, empero, tarea sencilla y tiempo habrá en los próximos meses para analizar las posibilidades que vayan, en su caso, poniéndose en juego. Pero corresponderá, en definitiva, a los Estados decidir si sigue mereciendo la pena la adhesión al CEDH... Con todo, el daño causado al diálogo judicial en el espacio jurídico europeo ya está hecho, no siendo descartable que pueda tener consecuencias indirectas añadidas en el diálogo con el TEDH y también con los Tribunales Constitucionales.

\section{CONSIDERACIONES FINALES: UNA DE CAL Y OTRA DE ARENA}

\section{Una de cal...}

Así las cosas, con la perspectiva que brindan las seis décadas de jurisprudencia que el TJUE acarrea ya a sus espaldas, el balance que ha de hacerse de su papel en el proceso de construcción europea sólo puede ser calificado como excepcionalmente positivo. El Tribunal de Justicia, como actor de la constitucionalidad en el espacio jurídico europeo, ha contribuido de manera magistral al diseño de un ordenamiento nuevo, basado en la supranacionalidad y no exento de ciertos elementos de regusto inconfundiblemente federal, que no tiene parangón en la comunidad internacional. Ha sido el motor de un proceso de integración europea basado en el Derecho, que está conduciendo a un proceso de constitucionalización europea $^{126}$ en el que la interacción judicial en materia de derechos humanos entre

124 Vid supra.

125 J. Polakiewicz, «Accession to the European Convention on Human Rights (ECHR) — An Insiders's View Addressing One by One the CJEU's Objections in Opinion 2/13», Human Rights Law Journal 2016, vol. 36, pp. 10-22.

126 A juicio de algunos autores, se estaría impulsando una evolución desde la comunidad de Derecho europea (Rechtsgemeinschaft) a una comunidad de valores cosmopolita (Wertgemeinschaft). Vid. P. BERTHELET, «De la Rechtgemeinschaft européenne à la Wertgemeinschaft cosmopolitique, la constitutionnalisation du droit de l'Union sous le signe des valeurs", Revue du Droit de l'Union Européen 2016, pp. 315-355. A juicio de este autor, en el Estado de Derecho europeo el equilibrio entre principios y valores antagonistas resulta central, jugando en este contexto el TJUE un papel decisivo a través del diálogo con las jurisdicciones nacionales. Así, 
los tres tribunales ya mencionados vendría a conformar una suerte de 'código genético' del Estado de Derecho europeo ${ }^{127}$.

En realidad, el TJUE ha podido desempeñar este papel jurídico protagonista gracias al constructivo y efectivo diálogo judicial desplegado con los otros dos vértices del 'triángulo judicial' europeo. Dicho diálogo es, en verdad, conditio sine qua non para el funcionamiento armónico del sistema constitucional multinivel, que se está construyendo en el espacio jurídico europeo; sin él se torna en quimera jurídica cualquier pretensión integradora. Incluso este diálogo judicial podría servir indirectamente como catalizador complementario para dotar de una legitimidad (jurídica) suplementaria al nuevo sistema multinivel que se está configurando en el continente europeo ${ }^{128}$. En este escenario, por lo que respecta al diálogo entre el TJUE y los Tribunales Constitucionales nacionales podría hablarse, pues, de una historia de ambiciones (constitucionales) comunes razonablemente bien resuelta. $Y$ el diálogo entre el TJUE y el TEDH ha logrado, además, una suerte de cross-fertilization entre ambos subsistemas de Derecho Internacional, alejándose cada vez más de la esfera iusinternacional (sin abandonarla), a la vez que, a través de sus respectivas interacciones con los Tribunales Constitucionales nacionales, ha conseguido integrar armónicamente esos dos subsistemas internacionales en los Derechos constitucionales de sus Estados miembros ${ }^{129}$.

Se ha configurado, de este modo, un espacio jurídico caracterizado por haber engendrado un sistema constitucional multinivel basado en un pluralismo jurídico que era desconocido en los esquemas pasados fundados en el Estado-nación, en la noción de soberanía y en el esquema kelseniano de pirámide normativa; un sistema fundado más en la idea de coherencia que en la de unidad, en el que la noción de diálogo judicial resulta elemento imprescindible ${ }^{130}$. Posiblemente, hasta se esté pro-

a través de la preservación de los derechos fundamentales, ha nacido una comunidad jurisdiccional transnacional. Es más, «les juges, à travers leur dialogue fécond, ont cette capacité d'imaginaire social instituant, capables de faire émerger une communauté de valeurs source d'unité politique» (p. 354 in fine).

127 Esta consideración se desarrolla en E. Dubout y S. Touzé, «La fonction des droits fondamentaux dans les rapports entre ordres et systèmes juridiques», en ib. (dirs.), Les droits fondamentaux: charnières entre ordres et systèmes juridiques, Pedone, Paris, Pedone, París, 2009, pp. 11-35, especialmente p. 20.

128 No es este el lugar idóneo para adentrarnos en la interesante cuestión de si los órganos jurisdiccionales (sea el TJUE o sean los propios Tribunales Constitucionales) pueden, en cierta forma, entrar en competición con los parlamentos a la hora de dotar de legitimidad al sistema mediante el que se organicen las respectivas comunidades políticas (Unión y Estados miembros). Véanse, sobre esta cuestión, las reflexiones de P. Cruz Villalón, «Legitimidad activa y legitimidad pasiva de los tribunales constitucionales en el espacio constitucional europeo», Teoría y Realidad Constitucional 2014, n. ${ }^{\circ} 33$, pp. 141-150.

129 F. B. JacoBs, «Judicial Dialogue and the Cross-Fertilization of Legal Systems: The European Court of Justice», Texas International Law vol. 38, 2003, pp. 547-556.

130 En este sentido, existe campo virgen más que suficiente para que la doctrina iuspublicista avance en la elaboración de una dogmática sobre la coberencia — más que sobre una unidad en un único ordenamiento jurídico multinivel imposible en la actualidad- de los diferentes órdenes jurídicos que conviven en el aludido espacio jurídico europeo; cfr. E. Schmidt-AbMann, «Einheit und Kohärenz der europäischen Mehrebenenrechtsordnung», Europäische Grundrechte-Zeitschrift 2016, vol. 43, pp. 85-92. Además de otros elementos como los mecanismos de cooperación reglada, los elementos procedimentales de creación de normas o las 
duciendo a la vez una retroalimentación entre jurisdicciones de diferentes regiones, especialmente entre la europea y la interamericana. No en vano, el modelo europeo no solo está sirviendo de espejo en otras regiones, sino que también está siendo objeto de atenta curiosidad por la doctrina de todo el planeta.

\section{2. ...y otra de arena}

Ahora bien, las mencionadas y bien merecidas loas al TJUE no son óbice para reconocer a renglón seguido que, en lo que se refiere a su concreta relación con el TEDH, el Alto Tribunal de la Unión no ha estado a la altura esperable. No se ha aplicado a sí mismo las exigencias que, con gran soltura (y brillantez jurídica), ha impuesto a los Tribunales Constitucionales. De la misma forma que éstos aceptaron en sus respectivas jurisprudencias Solange las exigencias del ordenamiento jurídico de la Unión marcadas por el TJUE, éste debería haber hecho lo propio respecto de las exigencias que, con idéntica naturalidad (y voluntad expresa de los Estados que redactaron el artículo 6.2 TUE) marca el TEDH a propósito del control judicial externo por él en materia de derechos fundamentales. No ha sido, sin embargo, el caso y, a nuestro juicio, este comportamiento merece una severa crítica. El TJUE ha abanderado en el dictamen 1/13 una posición que refleja una insostenible aspiración a aislar hasta el extremo las peculiaridades del Derecho de la Unión. En no pocos pasajes del dictamen se aprecia la sensación de un ejercicio de 'prefabricación argumental' y, desde luego, la constatación de una absoluta desconfianza frente al TEDH, por no decir una aspiración 'egojurídica' del Derecho de la Unión difícilmente aceptable para otros ordenamientos ${ }^{131}$; y poco compatible con esquemas conceptuales pluralistas o multinivel ${ }^{132}$. No conviene olvidar, a este respecto, que el diálogo judicial se fundamenta, por encima de todo, en el etéreo valor de la auctoritas del órgano jurisdiccional en cuestión; y ésta cuesta mucho conseguirla, como muy merecidamente se la ha ganado el TJUE, pero puede dilapidarse fácilmente ${ }^{133}$.

cuestiones de fijación de rangos normativos, cobra particular protagonismo el diálogo judicial entre los tribunales de vocación constitucional que conviven en el espacio jurídico en cuestión. Sin él, será tarea imposible construir tal dogmática y hará infructuosa la tarea de desterrar en este nuevo sistema multinivel viejas ideas ancladas en el orden jurídico piramidal del Estado-nación, como las de jerarquía en el ámbito normativo o las de última palabra en el campo judicial.

131 Con cierta ironía se ha hablado de que el Tribunal de Justicia «reclama un universo jurídico único con primacía del Derecho de la Unión»; Tomuschat, C.: «Der Streit um die Auslegunshoheit: Die Autonomie der EU als Heiliger Gral — Das EuGH-Gutachten gegen den Beitritt der EU zur EMRK», Europäsiche Grundrechte Zeitschrift 2015, pp. 133-139, en p. 137.

132 Como se ha afirmado con cierta gracia por algún autor, quiere responder al dicho 'lávame, pero no me mojes'; M. Breuer: «Wasch mir den Pelz, aber macht mich nicht nass! Das zweite Gutachten des EuGH zum EMRK-Beitritt der Europäischen Union», Europarecht 2015, pp. 330-350.

133 A este respecto, quizá no esté de más reflexionar muy seriamente sobre la realidad práctica actual derivada del sistema de reclutamiento de los jueces que integran los tres tribunales del 'triángulo judicial europeo» aquí tratado; véase por ejemplo, F. GARcía RocA, «La selección de los Magistrados del Tribunal 
En suma, bien puede afirmarse que Luxemburgo está en deuda con Estrasburgo; y las deudas conviene saldarlas lo antes posible. El TJUE ya no lo hará a tiempo, pues de manera inexplicable entró en mora cuando desperdició en diciembre de 2014 la oportunidad de oro que le brindaba el dictamen 2/2013 para cerrar adecuadamente el círculo de la protección constitucional de los derechos humanos en el espacio jurídico europeo. Confiemos, en todo caso, en que el Tribunal encuentre la forma de ponerse al día antes de que la situación se vuelva imposible; o al menos antes de que la reacción del TEDH se plasme en una revisión expresa de la doctrina Bosphorus y abra una suerte de 'guerra judicial' que nadie desea y que a nadie beneficiaría. Al que menos al TJUE.

$$
* * *
$$

TITLE: The Court of Justice of the EU as a constitutional actor

ABSTRACT: The Court of Justice of the European Union (CJEU) has played a significant role as a constitutional actor in the European legal space. It has decisively contributed to outline a new multilevel legal order, based on supranationality and with unmistakably federal elements unparalleled in the international community. The CJEU has been, thus, the driving forcé bebind the increasing process of European constitutionalisation. In this new European constitutional space a kind of constitutional judicial triangle has been created, which is integrated by the CJEU, the national Constitutional courts and the European Court of Human Rights (ECtHR). In this space, the judicial dialogue among the three vertex of this triangle is a sine qua non condition for a harmonic functioning of the system. In practice, the dialogue between the CJEU and the Constitutional courts has been reasonably solved, although nowadays certain problems pertaining to the control of ultra vires acts of the Union by the domestic Constitutional courts have emerged. The same can be said about the complicated realization of the notion of 'constitutional identity' as a limit to the actions of the Union. On the other hand, the dialogue between the CJEU and the ECtHR has been impacted by the objectionable decision of the CJEU regarding the EU's accession to the ECHR.

RESUMEN: El Tribunal de Justicia de la Unión Europea (TJUE) ha jugado un papel de primer orden como actor de la constitucionalidad en el espacio jurídico europeo. Ha contribuido de manera decisiva al diseño de un ordenamiento multinivel nuevo, basado en la supranacionalidad y con elementos de naturaleza inconfundiblemente federal que no tiene parangón en la comunidad internacional. Ha sido así el motor de un proceso de integración europea basado en el Derecho, que está conduciendo a un progresivo proceso de constitucionalización europea. En este nuevo escenario constitucional europeo se ha creado una suerte de triángulo judicial constitucional, integrado por el TJUE, los Tribunales Constitucionales nacionales y el Tribunal Europeo de Derechos Humanos (TEDH), en el que el diálogo judicial entre los tres vértices de este triángulo es condición sine qua non para el funcionamiento armónico del sistema. En la práctica, el diálogo entre el TJUE y los Tribunales Constitucionales ha sido razonablemente bien resuelto, si bien actualmente se plantea cierta problemática en relación con el posible control por los Tribunales constitucionales nacionales de actuaciones ultra vires de la Unión, así como en relación con la nada fácil concreción del concepto de 'identidad constitucional' como límite a la actuación de la Unión. Por otro lado, el diálogo entre el TJUE y el TEDH ha encontrado el obstáculo que plantea la criticable decisión del TJUE en relación con la adhesión de la UE al CEDH.

Constitucional, su estatuto y la necesaria regeneración de las instituciones», Revista General de Derecho Constitucional 2012, n. ${ }^{\circ}$ 15; A. vON BOGDANDY: «Zur demokratischen Legitimation von Europas Richtern. Eine vergleichende Rekonstruktion der Richterauswahl zu EGMR und EuGH», Juristenzeitung 2014, n. ${ }^{\circ}$ 11, pp. 529-537. 
KEY WORDS: Judicial dialogue; European Court of Justice; Constitutional Courts; European Court of Human Rights; constitutional identity; European judicial triangle.

Palabras Clave: Diálogo judicial, Tribunal de Justicia de la Unión Europea, Tribunales Constitucionales, Tribunal Europeo de Derechos Humanos, identidad constitucional, triángulo judicial europeo.

FECHA DE RECEPCIÓN: 10.01.2017

FECHA DE ACEPTACIÓN: 01.02.2017 
